\title{
Classifying Aerosols Based on Fuzzy Clustering and Their Optical and Microphysical Properties Study in Beijing, China
}

\author{
Wenhao Zhang, Hui Xu, and Fengjie Zheng \\ Institute of Remote Sensing and Digital Earth, Chinese Academy of Sciences, Beijing 100101, China \\ Correspondence should be addressed to Hui Xu; xhradi@163.com
}

Received 14 March 2017; Revised 27 May 2017; Accepted 4 June 2017; Published 24 July 2017

Academic Editor: Harry D. Kambezidis

Copyright ( 2017 Wenhao Zhang et al. This is an open access article distributed under the Creative Commons Attribution License, which permits unrestricted use, distribution, and reproduction in any medium, provided the original work is properly cited.

\begin{abstract}
Classification of Beijing aerosol is carried out based on clustering optical properties obtained from three Aerosol Robotic Network (AERONET) sites. The fuzzy c-mean (FCM) clustering algorithm is used to classify fourteen-year (2001-2014) observations, totally of 6,732 records, into six aerosol types. They are identified as fine particle nonabsorbing, two kinds of fine particle moderately absorbing (fine-MA1 and fine-MA2), fine particle highly absorbing, polluted dust, and desert dust aerosol. These aerosol types exhibit obvious optical characteristics difference. While five of them show similarities with aerosol types identified elsewhere, the polluted dust aerosol has no comparable prototype. Then the membership degree, a significant parameter provided by fuzzy clustering, is used to analyze internal variation of optical properties of each aerosol type. Finally, temporal variations of aerosol types are investigated. The dominant aerosol types are polluted dust and desert dust in spring, fine particle nonabsorbing aerosol in summer, and fine particle highly absorbing aerosol in winter. The fine particle moderately absorbing aerosol occurs during the whole year. Optical properties of the six types can also be used for radiative forcing estimation and satellite aerosol retrieval. Additionally, methodology of this study can be applied to identify aerosol types on a global scale.
\end{abstract}

\section{Introduction}

Aerosol is one of the largest sources of uncertainty in the radiative forcing and plays a key role in global climate change $[1,2]$. It has been identified that aerosols directly influence the earth's energy budget and indirectly alter the cloud processes $[3,4]$. Furthermore, different types of atmospheric aerosols will also lead to different radiative effects, which depend on their optical and microphysical properties [5]. For example, the present of strong absorbing aerosols like black carbon will lead to a positive radiative forcing (warming). On the contrary, the presence of nonabsorbing aerosols, such as fine hygroscopic particles (sulfate for example), will result in a negative radiative forcing (cooling) $[6,7]$. In addition, this uncertainty arises in regions where aerosol particles are contributed by complex components and show significant spatial and temporal variability [8]. Therefore, it is necessary to understand different types of aerosol properties (especially in regions with higher concentration of aerosols, such as China, where they are found with a high positive trend of AOD from 2001 to 2010 [9]) to reduce their uncertainty in radiative forcing estimates and other related scientific fields.

To better depict aerosol properties, many studies were carried out in the last decades [10-17]. Some of the studies [10-13] classify aerosol types by thresholds of aerosol properties, such as aerosol optical depth (AOD), Ångström exponent (AE), fine-mode fraction (FMF), single scattering albedo (SSA), or their combinations. For example, to discriminate aerosol types of biomass-urban, desert dust, clean maritime, and mixed-type, appropriate thresholds for AOD and AE are applied [10]. In addition, by using SSA and FMF observed by Aerosol Robotic Network (AERONET), Lee et al. (2010) classified global aerosol into four types; they are dust, nonabsorbing, black carbon, and mixture [13]. However, in these methods, characteristics of aerosol types at one location or site are represented by mean values of measurements. The shortcomings are obvious because aerosol properties are easily affected by meteorology events such as wind and rain [18]. Thus, aerosol type can be changed as short as a few hours. Besides, in regions affected by multiple aerosol sources (such as China, which is affected by dust from desert, 
biomass burning aerosol from agriculture, and black carbon from industrial emissions $[13,19])$ the temporal distributions and characteristics are rather complex. Consequently, mean values of long-term aerosol properties observations are insufficient to represent characteristics of aerosol types [14].

To overcome this shortcoming, the others [14-17] take advantage of clustering to classify aerosol types. Clustering is a statistical tool used for grouping a set of objects into several clusters using predefined variables, so that objects in the same cluster are more similar to each other than those in other clusters. Omar et al. (2005) applied cluster analysis to global ground-based observations and obtained six categories: background/rural, industrial pollution, dirty pollution, biomass burning, desert dust, and polluted marine [14]. In addition, Levy et al. (2007) performed a "subjective" cluster analysis for AERONET records, which were divided into three fine-sized dominated spherical types (typically the "low," "medium," and "high" absorbing types) and one coarse-sized dominated spheroid type [15]. Besides, Qin and Mitchell (2009) applied Locally Scaled Density Based Clustering (LSDBC) algorithm to classify Australian aerosol into four classes including aged biomass burning smoke, fresh smoke, coarse dust, and super-absorptive aerosol [16]. These results show that cluster analysis is suitable for classifying aerosol types. However, the limitation of these classifications is that the values of cluster center are used to represent the characteristics of corresponding aerosol types. As a matter of fact, the differences between records at edge of cluster and those near center are inevitable. Particularly for multiparticles mixture aerosol, records are usually on the boundaries between several clusters, and only representing them by the center of each cluster is unreasonable [20]. To overcome this limitation, Wu and Zeng (2014) applied Gustafson-Kessel fuzzy clustering algorithm to identify the optical properties of pure dust aerosol type [20]. Compared with aforementioned clustering algorithm, not only center of cluster but also a significant parameter named membership degree (between 0 and 1 ) is provided by fuzzy clustering. The membership degree is used to describe the confidence degree of one record belonging to a cluster. The records near the center of cluster will have larger value of membership (higher degree of confidence) than those at edge. Thus, membership degree will be helpful to analyze the internal variation of optical properties within each aerosol type. The capability of fuzzy cluster analysis to obtain aerosol properties in single type dominant regions has been documented, whereas its capacity to obtain aerosol properties in regions which are frequently influenced by various sources of aerosols still has not been well reported.

Beijing, one of the largest megacities in the world, has been suffering severe issues of aerosols loading for decades because of rapid development of both economy and population. It is famous for its complex aerosol particles and high proportion of anthropogenic aerosols. Due to its importance to climate and environment, many studies were carried out to obtain the aerosol properties in this region. The researchers are interested in (i) characteristics of fine or coarse particle aerosols [21, 22]; (ii) components and sources [23, 24]; (iii) aerosol optical properties [25-29]. Nevertheless, the dominant aerosol types and their temporal variation still have not been well reported. But the definite aerosol types are important to improve radiative forcing estimation and satellite aerosol retrieval. To this end, this paper focuses on classifying identical aerosol types and studying their optical properties.

In this study, long-term (14 years) observations of AERONET are used to determine dominant aerosol types and their optical properties over Beijing. One of the most widely used fuzzy clustering algorithms, fuzzy $c$-mean (FCM) algorithm [30], is applied to classify distinct aerosol types. This is the first comprehensive study investigating aerosol types and their temporal distribution in Beijing. This work will provide a primary parameter for the estimation of aerosol radiative forcing and retrieval of aerosol properties from satellite aerosol, as well as reference for methodology of identifying aerosol types in other regions. The paper is structured as follows: Section 2 briefly describes the dataset and method used in this study; a detailed analysis of aerosols properties is conducted in Section 3; at last, the conclusions are drawn in Section 4.

\section{Data and Methodology}

2.1. Description of Aerosol Sites and Data. The AERONET is a global network of ground-based CIMEL sun-sky radiometer. AERONET inversion products include a comprehensive data set of aerosol optical and microphysical properties: aerosol optical depth (AOD) at 340, 380, 440, 500, 675, 870, and $1020 \mathrm{~nm}$, the single scattering albedo (SSA), complex refractive indices, asymmetry parameter (ASYM) at four wavelengths $(440,676,869$, and $1020 \mathrm{~nm})$, and the parameters of particle size distribution [31, 32].

In this study, three AERONET sites (surrounding Beijing City) are selected; they are Beijing, Xianghe, and Xinglong. By choosing these sites over 14 years (2001-2014), a total of 6,732 records are obtained. It should be noted that we collect records of AERONET “All Points" Level 2.0 inversion products, which can be obtained from http://aeronet .gsfc.nasa.gov/. Figure 1 and Table 1 show the detailed information of the selected sites.

The following 22 parameters obtained from AERONET inversion products are applied in the cluster analysis:

(a) Single scattering albedo (SSA) at 440, 676, 869, and $1020 \mathrm{~nm}$

(b) Real part of refractive index (REFR) at 440, 676, 869, and $1020 \mathrm{~nm}$

(c) Imaginary part of refractive index (REFI) at 440, 676, 869 , and $1020 \mathrm{~nm}$

(d) Asymmetry parameter (ASYM) at 440, 676, 869, and $1020 \mathrm{~nm}$

(e) Parameters of particle size distribution: fine/coarse particle volume concentration (VolConF/VolConC); fine/coarse particle volume median radius (VolMedianRadF/VolMedianRadC); fine/coarse particle standard deviation (StdDevF/StdDevC). 


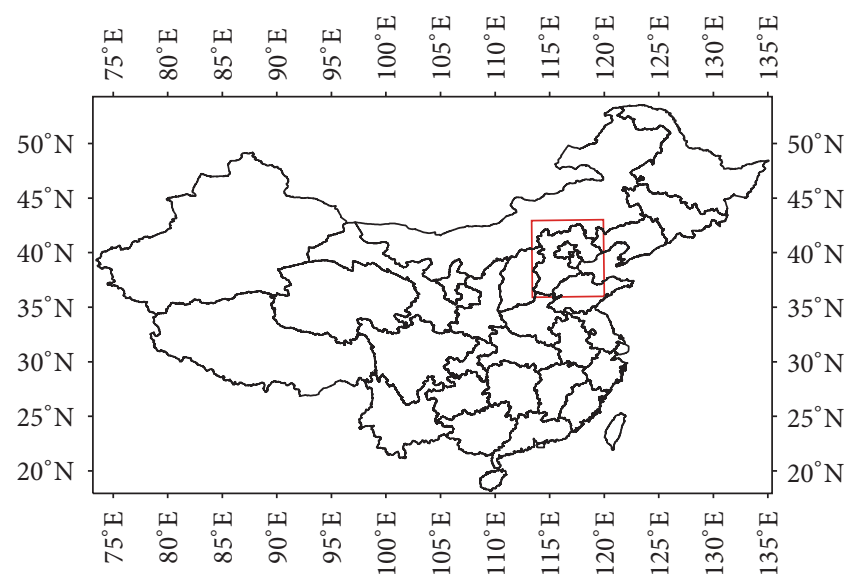

(a)

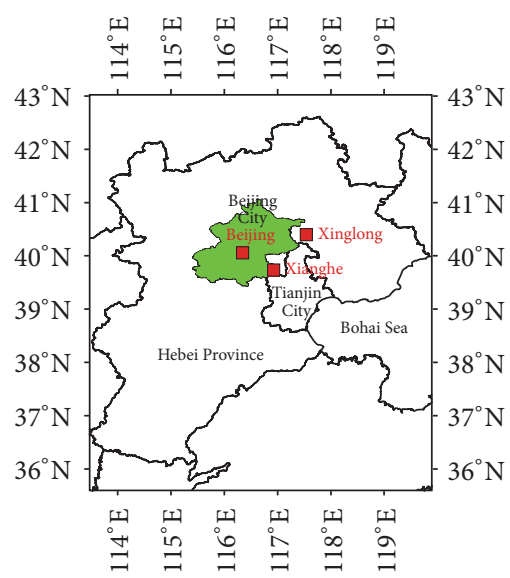

(b)

FIGURE 1: Geographical location of the selected three AERONET sites.

TABLE 1: Information of the selected three AERONET sites.

\begin{tabular}{lccccc}
\hline Site name & Observing period & Number of records & $\begin{array}{c}\text { Longitude } \\
\text { (degree) }\end{array}$ & $\begin{array}{c}\text { Latitude } \\
\text { (degree) }\end{array}$ & $\begin{array}{c}\text { Elevation } \\
(\text { meter })\end{array}$ \\
\hline Beijing & $2001-2014$ & 3418 & 116.381 & 39.977 & 92 \\
Xianghe & $2001,2004-2012$ & 2797 & 116.962 & 39.754 & 36 \\
Xinglong & $2006-2012$ & 517 & 117.578 & 40.396 & 970 \\
\hline
\end{tabular}

It should be noted that the aerosol optical depth (AOD), fine fraction by volume (FFV), sphericity parameter (SP), and water vapor (WV) are also used in later discussions. However, these four parameters are not applied in clustering.

2.2. Fuzzy Clustering. Cluster analysis is a statistical tool used for grouping the data sets into several clusters based on predefined variables [14]. The basic theory of cluster analysis is records in the same cluster which are more similar to each other than to those in other clusters. In fuzzy clustering, every record has a degree of belonging to each cluster, rather than just completely belonging to one cluster [20]. This degree is represented by a parameter named membership degree (between 0 and 1), which indicates the confidence degree of one record belonging to a cluster. The records on the boundary of cluster will have smaller values than those near the center.

In this study, fuzzy $c$-mean (FCM) algorithm, one of the most widely used fuzzy clustering algorithms, is applied. Given the data set containing $n$ records, $X=\left\{x_{1}, x_{2}, \ldots, x_{n}\right\}$, and supposing there are $c$ clusters with the centers, $V=$ $\left\{v_{1}, v_{2}, \ldots, V_{c}\right\}$. The FCM aims to minimize the objective function:

$$
\min J(u, v)=\sum_{k=1}^{n} \sum_{i=1}^{c} \mu_{i k}^{m} d_{i k}^{2}
$$

where $d_{i k}^{2}=\left\|x_{k}-v_{i}\right\|^{2}$ represents the distance between record $x_{k}$ and center $v_{i}$. And $\mu_{i k}^{m}$ is the degree to which record $x_{k}$ belongs to cluster $v_{i}$ and is defined as

$$
u_{i k}=\frac{1}{\sum_{j}^{c}\left(\left\|x_{k}-v_{i}\right\| /\left\|x_{k}-v_{j}\right\|\right)^{2 /(m-1)}} .
$$

For a certain record, $\sum_{i}^{c} u_{i k}=1$. The fuzzifier $m$ determines the level of cluster fuzziness, meaning the overlapping degree of the cluster, and $m \geq 1$. The center of the cluster is defined as

$$
v_{i}=\frac{\sum_{k=1}^{n} u_{i k}^{m} x_{k}}{\sum_{k=1}^{n} u_{i k}^{m}} .
$$

The step of FCM is described as follows. Firstly, a random function is used to determine the initial center of each cluster. Calculate membership degree and objective function based on functions (1) and (2). Meanwhile centers of each cluster are calculated based on function (3). Repeat until the algorithm has converged; that is, the membership degree change between two iterations is no more than the given sensitivity threshold. It should be noted that before clustering the 22 parameters are normalized by the standard deviation, to ensure that each parameter makes the same contribution to the distance calculation.

\section{Results and Discussions}

3.1. Results. By applying the FCM clustering, a total of 6732 records are classified into six clusters. The characteristics of optical and microphysical properties of each cluster center are shown in Table 2. Figure 2 displays aerosol optical depth, single scattering albedo, asymmetry parameter, fine fraction by volume, sphericity parameter, and water vapor of each cluster center. Figure 3 shows the particle size distributions 
TABLE 2: Results of the fuzzy cluster analysis.

\begin{tabular}{|c|c|c|c|c|c|c|c|}
\hline \multicolumn{2}{|c|}{ Properties } & Cluster 1 & Cluster 2 & Cluster 3 & Cluster 4 & Cluster 5 & Cluster 6 \\
\hline \multirow{4}{*}{ AOD } & $440 \mathrm{~nm}$ & 1.25 & 1.56 & 0.79 & 0.76 & 0.73 & 0.87 \\
\hline & $676 \mathrm{~nm}$ & 0.77 & 0.94 & 0.45 & 0.43 & 0.44 & 0.64 \\
\hline & $869 \mathrm{~nm}$ & 0.54 & 0.66 & 0.31 & 0.31 & 0.33 & 0.55 \\
\hline & $1020 \mathrm{~nm}$ & 0.42 & 0.54 & 0.26 & 0.26 & 0.28 & 0.51 \\
\hline \multirow{4}{*}{ SSA } & $440 \mathrm{~nm}$ & 0.95 & 0.90 & 0.90 & 0.84 & 0.88 & 0.89 \\
\hline & $676 \mathrm{~nm}$ & 0.96 & 0.92 & 0.91 & 0.87 & 0.91 & 0.94 \\
\hline & $869 \mathrm{~nm}$ & 0.95 & 0.91 & 0.90 & 0.85 & 0.90 & 0.95 \\
\hline & $1020 \mathrm{~nm}$ & 0.95 & 0.90 & 0.90 & 0.84 & 0.90 & 0.95 \\
\hline \multirow{4}{*}{ REFR } & $440 \mathrm{~nm}$ & 1.44 & 1.50 & 1.43 & 1.48 & 1.51 & 1.50 \\
\hline & $676 \mathrm{~nm}$ & 1.44 & 1.51 & 1.46 & 1.51 & 1.53 & 1.53 \\
\hline & $869 \mathrm{~nm}$ & 1.44 & 1.52 & 1.47 & 1.52 & 1.54 & 1.53 \\
\hline & $1020 \mathrm{~nm}$ & 1.44 & 1.51 & 1.48 & 1.53 & 1.54 & 1.52 \\
\hline \multirow{4}{*}{ REFI } & $440 \mathrm{~nm}$ & 0.007 & 0.015 & 0.012 & 0.023 & 0.014 & 0.007 \\
\hline & $676 \mathrm{~nm}$ & 0.005 & 0.009 & 0.008 & 0.014 & 0.008 & 0.003 \\
\hline & $869 \mathrm{~nm}$ & 0.005 & 0.009 & 0.008 & 0.015 & 0.008 & 0.003 \\
\hline & $1020 \mathrm{~nm}$ & 0.005 & 0.010 & 0.009 & 0.016 & 0.008 & 0.003 \\
\hline \multirow{4}{*}{ ASYM } & $440 \mathrm{~nm}$ & 0.74 & 0.71 & 0.71 & 0.68 & 0.69 & 0.72 \\
\hline & $676 \mathrm{~nm}$ & 0.70 & 0.65 & 0.64 & 0.62 & 0.64 & 0.68 \\
\hline & $869 \mathrm{~nm}$ & 0.67 & 0.62 & 0.61 & 0.61 & 0.63 & 0.68 \\
\hline & $1020 \mathrm{~nm}$ & 0.65 & 0.62 & 0.61 & 0.61 & 0.63 & 0.69 \\
\hline \multicolumn{2}{|c|}{ VolConF $\left(\mu \mathrm{m}^{3} / \mu \mathrm{m}^{2}\right)$} & 0.16 & 0.17 & 0.11 & 0.09 & 0.08 & 0.07 \\
\hline \multicolumn{2}{|c|}{ VolMedianRadF $(\mu \mathrm{m})$} & 0.26 & 0.21 & 0.17 & 0.16 & 0.16 & 0.15 \\
\hline \multicolumn{2}{|c|}{ StdDevF } & 0.57 & 0.54 & 0.50 & 0.51 & 0.48 & 0.52 \\
\hline \multicolumn{2}{|c|}{ VolConC $\left(\mu \mathrm{m}^{3} / \mu \mathrm{m}^{2}\right)$} & 0.09 & 0.18 & 0.11 & 0.11 & 0.16 & 0.35 \\
\hline \multicolumn{2}{|c|}{ VolMedianRadC $(\mu \mathrm{m})$} & 2.94 & 2.60 & 2.73 & 2.79 & 2.71 & 2.35 \\
\hline \multicolumn{2}{|c|}{ StdDevC } & 0.55 & 0.57 & 0.60 & 0.63 & 0.65 & 0.60 \\
\hline \multicolumn{2}{|c|}{ FFV } & 0.64 & 0.49 & 0.50 & 0.45 & 0.33 & 0.17 \\
\hline \multicolumn{2}{|c|}{ SP (\%) } & 52.32 & 57.83 & 58.28 & 64.27 & 28.99 & 6.51 \\
\hline \multicolumn{2}{|c|}{$\mathrm{WV}\left(\mathrm{g} / \mathrm{cm}^{2}\right)$} & 2.18 & 1.13 & 1.34 & 0.64 & 0.91 & 0.91 \\
\hline \multicolumn{2}{|c|}{ Number of records } & 917 & 1124 & 1188 & 1252 & 1394 & 857 \\
\hline \multicolumn{2}{|c|}{ Percentage to total number (\%) } & 13.6 & 16.7 & 17.6 & 18.6 & 20.7 & 12.7 \\
\hline
\end{tabular}

and Figure 4 represents the relationship between sphericity parameter and coarse fraction by volume.

\subsection{Characteristics of Aerosol Types}

3.2.1. Fine Particle Nonabsorbing Aerosol. As shown in Figure 2(d), cluster 1 exhibits the largest value of fine fraction by volume (FFV) that is 0.64 . Obviously, cluster 1 is fine particle dominated aerosol. Figure 3 shows the particle size distribution of cluster 1 described by a fine radius and standard deviation of $0.26 \mu \mathrm{m}$ and 0.57 and a coarse radius and standard deviation of $2.94 \mu \mathrm{m}$ and 0.55 . Moreover, this type of aerosol displays clearly nonabsorbing properties as the single scattering albedos (SSAs) at four wavelengths $(440,676,869$, and $1,020 \mathrm{~nm})$ are $0.95,0.96,0.95$, and 0.95 (Figure 2(b)), respectively. As shown in Table 2, the real parts of refractive index (REFRs) of cluster 1 at four wavelengths are 1.44 , which is lower than other clusters. According to Brown (1984), lower value of real part of refractive index is possibly associated with high hygroscopicity of aerosol [33]. When there is high relative humidity, water is usually attached to the surface of particle. As a result, it will enhance the ability of particle scattering incident wave. This analysis is consistent with large value of water vapor $\left(2.18 \mathrm{~g} / \mathrm{cm}^{2}\right)$ of cluster 1 , which is shown in Figure 2(f). Moreover, this type of aerosol is usually observed in summer (Section 3.4), in which season Beijing is less affected by smoke and dust. Therefore, it is likely that these fine nonabsorbing particles are mainly the emissions of heavy traffic and industrial factories.

There are similarities between cluster 1 and polluted continental classified by Omar et al. (2005) [14]. But the former is stronger in particle scattering and higher in fine fraction by volume. Consequently, we identified cluster 1 as fine particle nonabsorbing aerosol. To verify the relationship between fine particle nonabsorbing aerosol and air pollution of Beijing, we collected the data of air quality index (AQI) over one year (October 2013 to October 2014) of Beijing (because the data of AQI is not open to public, only 2013-2014 is available to 

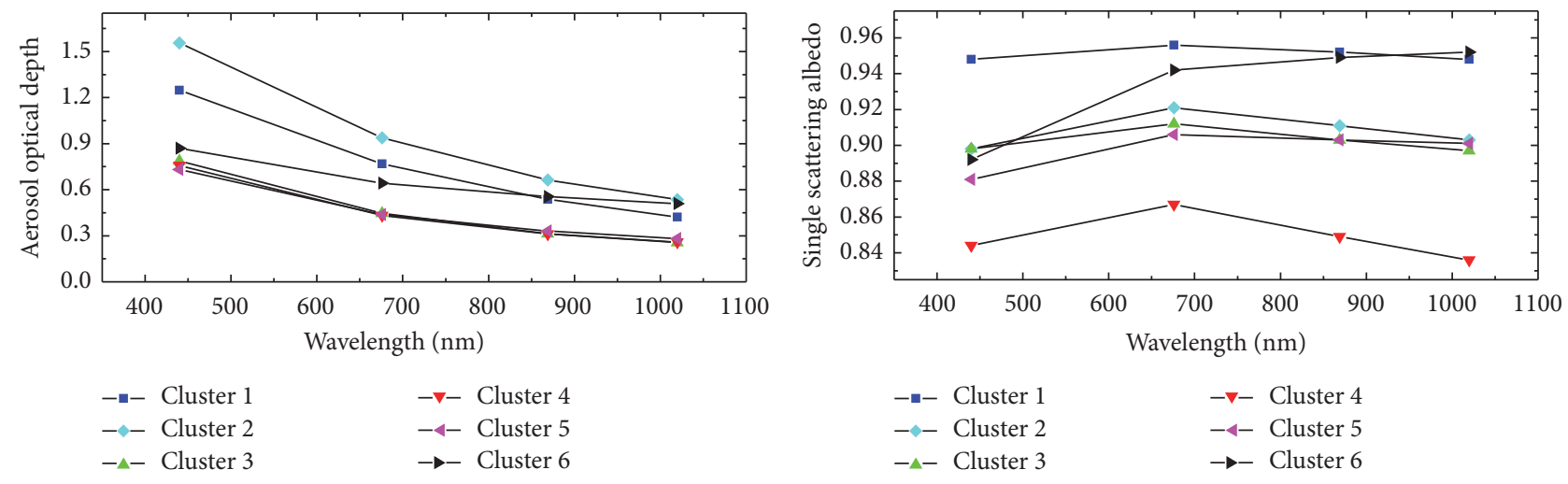

(a) AOD
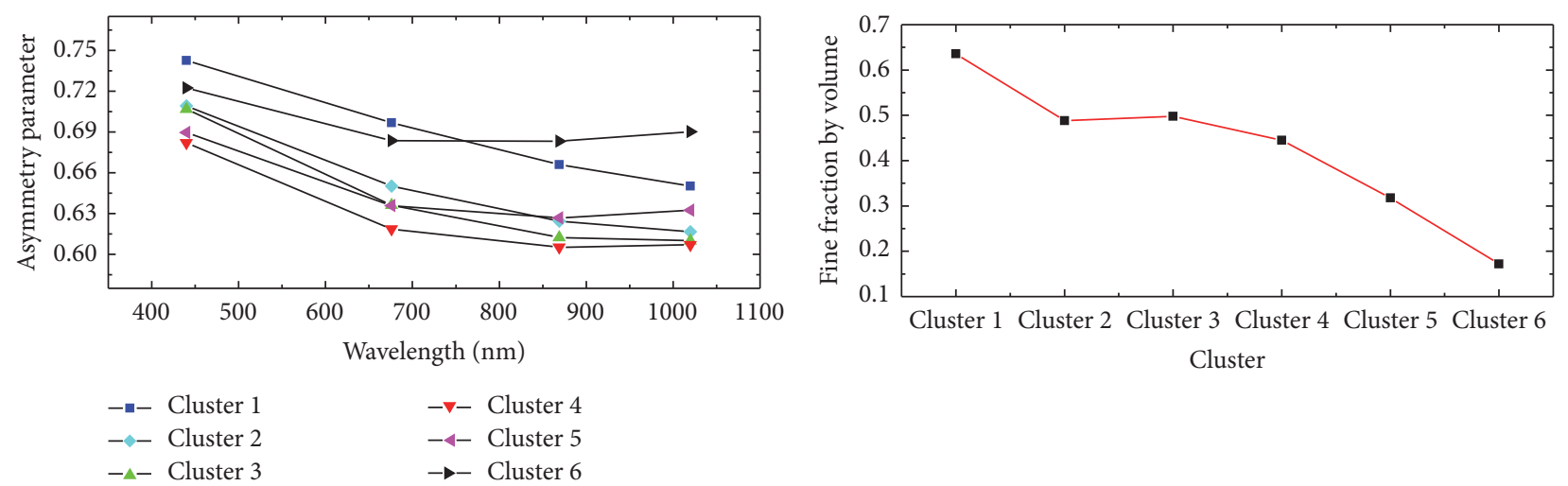

(c) ASYM

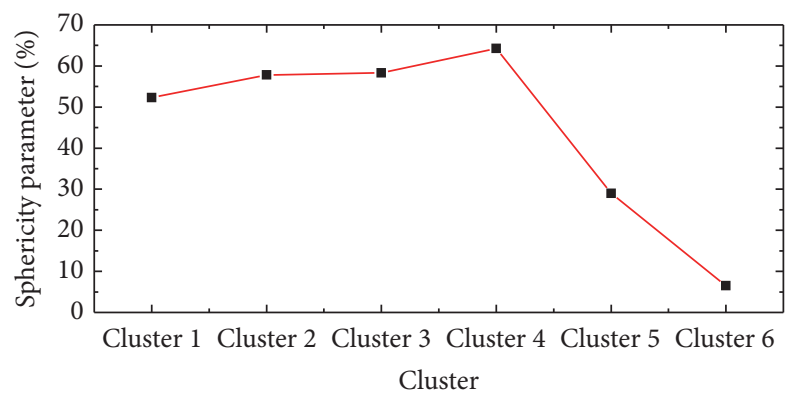

(e) SP

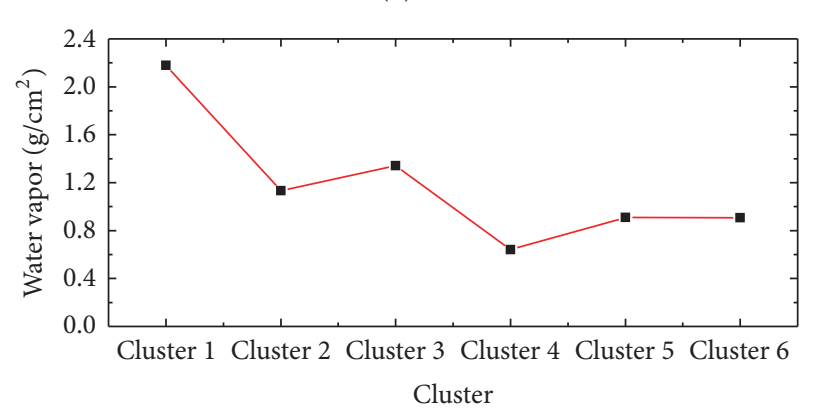

(f) WV

Figure 2: The characteristics of six cluster centers: (a) aerosol optical depth; (b) single scattering albedo; (c) asymmetry parameter; (d) fine fraction by volume; (e) sphericity parameter; (f) water vapor.

us). The AQI is an index that indicates the pollution level of the atmosphere, while a higher AQI value means a heavier atmospheric pollution. The value of AQI level increase from one to six represents air qualities of excellent, good, slight pollution, moderate pollution, heavy pollution, and severe pollution, respectively. Before comparison, we collocate AQI data with classified aerosol types and obtain 88 matchups. Figure 5 shows numbers of each aerosol type observed in per-AQI level over 2013-2014 at Beijing site. It can be seen from Figure 5 that fine particle nonabsorbing aerosol is most frequently observed at AQI level 4 (moderate pollution), followed by AQI-levels 5 (heavy pollution) and 6 (severe pollution).
3.2.2. Fine Particle Moderately Absorbing Aerosol. The fine fraction by volume of cluster 2 and cluster 3 is 0.49 and 0.50 , respectively. Besides, the SSAs at four wavelengths $(440,676$, 869 , and $1,020 \mathrm{~nm}$ ) are $0.90,0.92,0.91$, and 0.90 for cluster 2 and $0.90,0.91,0.90$, and 0.90 for cluster 3 . Therefore, both clusters are considered as fine particle moderately absorbing aerosols (cluster 2 and cluster 3 named as fine-MA1 and fineMA2, resp.).

The fine-MA1 and fine-MA2 aerosols are mainly distinguished by real parts of the refractive index (REFRs) and fine and coarse particle volume concentrations. The REFRs of fine-MA1 at four wavelengths are 1.50, 1.51, 1.52, and 1.51, respectively. Correspondingly, the REFRs of fineMA2 are much lower, with REFRs being 1.43, 1.46, 1.47, 


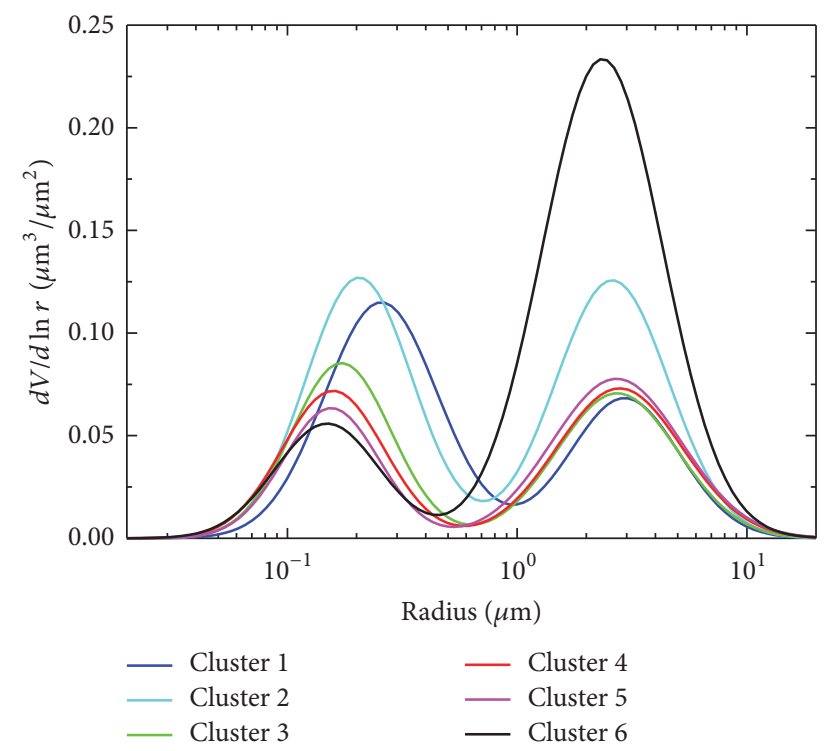

FIGURE 3: The particle size distributions of six cluster centers.

and 1.48. According to Bohren and Huffman (1983) [34], dry particle basically has a higher REFR, usually being 1.5-1.6. That is consistent with the fact that the water vapor of fine-MA1 $\left(1.13 \mathrm{~g} / \mathrm{cm}^{2}\right)$ is lower than that of fine-MA2 $\left(1.34 \mathrm{~g} / \mathrm{cm}^{2}\right)$, which can be seen in Figure 2(f). Additionally, the fine particle volume concentration of fine-MA1 is the largest one in six aerosol types $\left(0.17 \mu \mathrm{m}^{3} / \mu \mathrm{m}^{2}\right)$, and the coarse particle volume concentration is also found being high level $\left(0.18 \mu \mathrm{m}^{3} / \mu \mathrm{m}^{2}\right)$. Correspondingly, both fine and coarse particle volume concentration of fine-MA2 are much lower (both are $0.11 \mu \mathrm{m}^{3} / \mu \mathrm{m}^{2}$ ) than fine-MA1.

Compared with Omar et al. (2005) [14], fine-MA1 is like polluted continental aerosol and dirty pollution aerosol. But the absorption is lower than the former and higher than the latter. It can be seen from Figure 5 that fine-MA1 is the most frequently observed at AQI levels 5 and 6. Besides, fine-MA1 is just a little lower than fine particle nonabsorbing aerosol at AQI level 4. Furthermore, fine-MAl is hardly observed at AQI levels 1 (excellent) and 2 (good). On the contrary, fine-MA2 is characterized by a low optical depth (Figure 2(a)) and a high frequency of incidence at low AQI level when the atmosphere is expected to be relatively clean. The characteristics are more likely the background/rural aerosol classified by Omar et al. (2005) [14]. Consequently, fine-MA2 is possibly the background aerosol of Beijing.

3.2.3. Fine Particle Highly Absorbing Aerosol. Cluster 4 is of interest in view of its high absorption. The SSAs at four wavelengths $(440,676,869$, and $1,020 \mathrm{~nm})$ are $0.84,0.87,0.85$, and 0.84 (Figure 2(b)), respectively. Besides, the fine fraction by volume is 0.45 (Figure $2(\mathrm{~d})$ ). The fine particle volume concentration is $0.09 \mu \mathrm{m}^{3} / \mu \mathrm{m}^{2}$ and the coarse particle volume concentration is $0.11 \mu \mathrm{m}^{3} / \mu \mathrm{m}^{2}$. In addition, Figure 3 shows the particle size distribution of cluster 4 described by a fine radius and standard deviation of $0.16 \mu \mathrm{m}$ and 0.51 and coarse radius and standard deviation of $2.79 \mu \mathrm{m}$ and
0.63. Therefore, we identified cluster 4 as fine particle highly absorbing aerosol.

Figure 2(e) shows that the sphericity parameter (the higher value indicates the particle is closer to sphericity) of fine particle highly absorbing aerosol exhibits the largest value (64.27\%). Moreover, it can be clearly seen from Figure $4(\mathrm{~d})$ that this kind of aerosol has much more records with sphericity parameter higher than $90 \%$. It demonstrates that fine particle highly absorbing aerosol is more likely a spherical aerosol. These characteristics are like biomass burning aerosol classified by Omar et al. (2005) [14]. Additionally, it can be seen from Table 2 that the real parts of the refractive index at a high level are 1.48, 1.51, 1.52, and 1.53 at four wavelengths. According to the study result of Dubovik et al. (2002) [11], higher REFRs and lower SSAs are possibly associated with high concentrations of black carbon. Furthermore, this kind of aerosol usually occurs in winter (Section 3.4) in which season coal is frequently used for heating supply in northern China [23, 28]. Consequently, fine particle highly absorbing aerosol is possibly mainly produced by fossil fuel combustion.

3.2.4. Polluted Dust. Cluster 5 has the largest number of records, with $20.7 \%$ of total records being classified in this type. The SSAs at four wavelengths $(440,676,869$, and $1,020 \mathrm{~nm}$ ) are $0.88,0.91,0.90$, and 0.90 (Figure 2(b)), respectively. Besides, the fine fraction by volume is 0.33 (Figure 2(d)). The fine particle volume concentration is $0.08 \mu \mathrm{m}^{3} / \mu \mathrm{m}^{2}$, and coarse particle volume concentration is $0.16 \mu \mathrm{m}^{3} / \mu \mathrm{m}^{2}$. Figure 3 shows the particle size distribution of cluster 5 described by a fine radius and standard deviation of $0.16 \mu \mathrm{m}$ and 0.48 and coarse radius and standard deviation of $2.71 \mu \mathrm{m}$ and 0.65 . As shown in Figure 4(e), most records of cluster 5 fall within sphericity parameter lower than $50 \%$ and coarse fraction by volume higher than 0.5 . Thus, it indicates that cluster 5 is nonspherical coarse particle dominated aerosol. According to Okada et al. (2001), nonspherical coarse particle is possibly contributed by dust [35]. However, there is no significant difference between SSAs at $440 \mathrm{~nm}$ and longer wavelengths. But previous studies show that when wavelength changes from $440 \mathrm{~nm}$ to longer, the SSA will increase largely (Section 3.2.5) for dust aerosol. Besides, this kind of aerosol is frequently observed in spring (Section 3.4), in which season Beijing is affected by longrange transported dust. Thus, cluster 5 is possibly the dust mixes with anthropogenic aerosol. As shown in Figure 4(e), cluster 5 also has some records with high sphericity parameter or low coarse fraction by volume. Consequently, we identified cluster 5 as polluted dust. It should be noted that this polluted dust aerosol is the first time classified as a unique type by cluster analysis method. The fact that polluted dust can be identified by FCM demonstrates the practicability of fuzzy clustering in aerosol classification.

3.2.5. Desert Dust. Cluster 6 is significantly characterized by smallest fine fraction by volume (0.17) and lowest sphericity parameter $(6.51 \%)$. Besides, it shows the smallest fine particle volume concentration $\left(0.08 \mu \mathrm{m}^{3} / \mu \mathrm{m}^{2}\right)$ and largest coarse particle volume concentration $\left(0.16 \mu \mathrm{m}^{3} / \mu \mathrm{m}^{2}\right)$. It indicates 


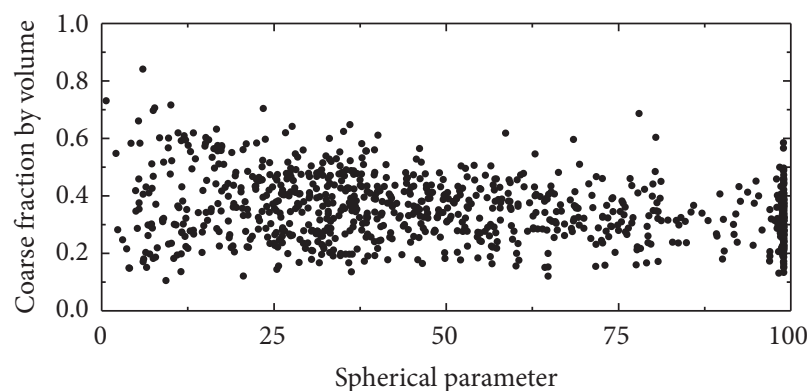

(a) Cluster 1

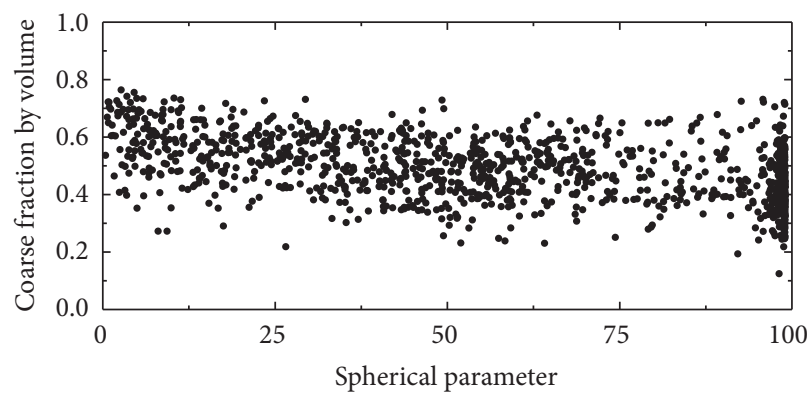

(c) Cluster 3

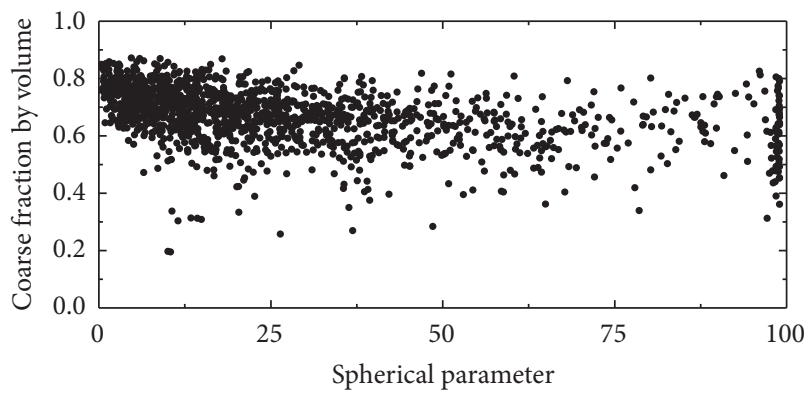

(e) Cluster 5

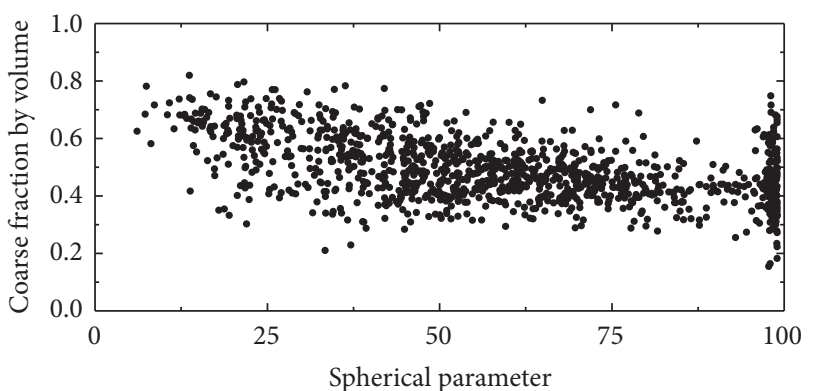

(b) Cluster 2

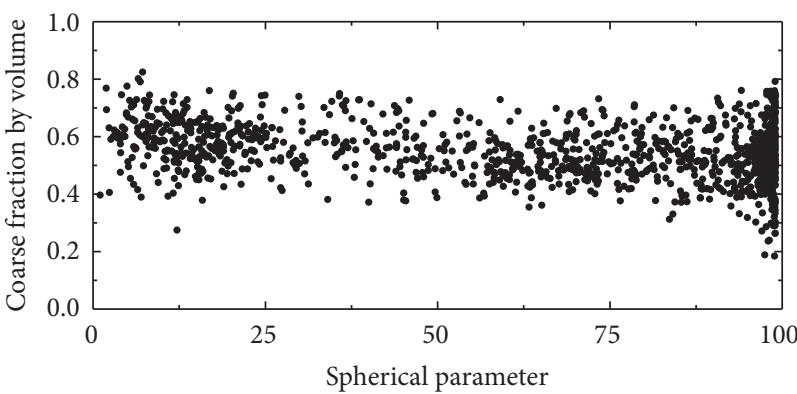

(d) Cluster 4

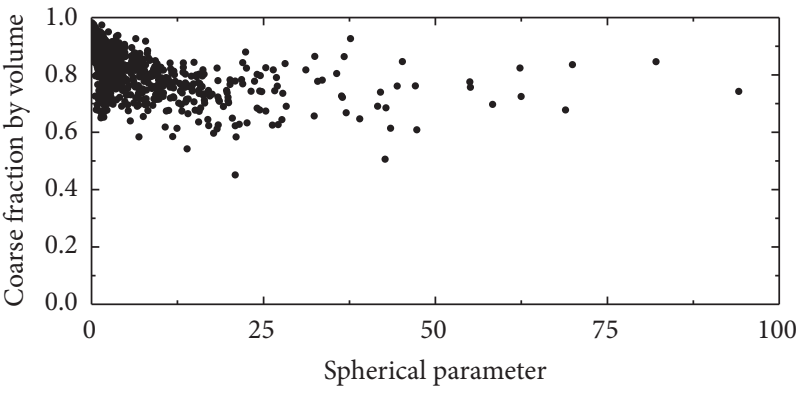

(f) Cluster 6

FIGURE 4: Relationships of sphericity parameter and coarse fraction by volume.

that this is a completely coarse particle dominated aerosol. In addition, as shown in Figure 4(f), most records of cluster 6 concentrate in the range of sphericity parameter lower than $15 \%$ and coarse fraction by volume higher than 0.6 . It demonstrates that cluster 6 is completely nonspherical coarse particles dominated aerosol. Moreover, the SSAs of cluster 6 exhibit a distinct feature, with lower value at $440 \mathrm{~nm}(0.89)$ and a sharp increase to $0.94,0.95$, and 0.95 at $660 \mathrm{~nm}, 896 \mathrm{~nm}$, and $1020 \mathrm{~nm}$ (Figure 2(b)), respectively. This is consistent with the characteristic of desert dust derived by Levy et al. (2007) [15] and Qin and Mitchell (2009) [16]. Furthermore, according to Dubovik et al. (2002) desert dust is possibly absorbed in the short spectral region due to the contained iron oxide hematite [11]. The SSA of dust particle might be lower at short wavelength regions when it contains the $\mathrm{FeO} 2$. Consequently, these characteristics clearly certify that cluster 6 is desert dust aerosol.

3.2.6. Comparison with Other Results. To assess the proposed fuzzy methodology, we take a comparative study of our result with other published researches in aerosol classification.
Considering study area and methodology, two published results are chosen, global aerosol types by Omar et al. (2005) [14] and East Asian aerosol types by Lee and Kim (2010) [17].

(1) Comparison with Global Aerosol Types. Omar et al. (2005) applied cluster analysis to global ground-based observations and obtained six categories: background/rural, industrial pollution, dirty pollution, biomass burning, desert dust, and polluted marine [14]. Their characteristics are shown in Table 3. Five of the six aerosol types, we classified, show similarities with Omar's global aerosol types; they are fine particle nonabsorbing aerosol to polluted continental aerosol, fine-MA2 to background aerosol, fine particle highly absorbing aerosol to biomass burning aerosol, and polluted dust and desert dust to dust.

Figures 6 and 7 demonstrate comparisons of characteristics of aerosol types between global and Beijing aerosol types, including particle size distributions, single scattering albedo, and asymmetry parameter. Particle size distributions (Figure 6) show that the values of $d V / d \ln r$ varied significantly between two researches. The particle volume concentration 
TABLE 3: Characteristics of global aerosol types by Omar et al. (2005).

\begin{tabular}{lcccccc}
\hline Properties (676 nm) & Polluted continental & Background/rural & Biomass burning & Dirty pollution & Dust & Marine \\
\hline SSA & 0.92 & 0.88 & 0.80 & 0.72 & 0.93 & 0.93 \\
REFR & 1.4098 & 1.4494 & 1.5202 & 1.4104 & 1.4520 & 1.3943 \\
REFI & 0.0063 & 0.0092 & 0.0245 & 0.0337 & 0.0036 & 0.0044 \\
ASYM & 0.612 & 0.580 & 0.603 & 0.594 & 0.668 & 0.711 \\
FFV & 0.53 & 0.38 & 0.33 & 0.49 & 0.22 & 0.26 \\
\hline
\end{tabular}

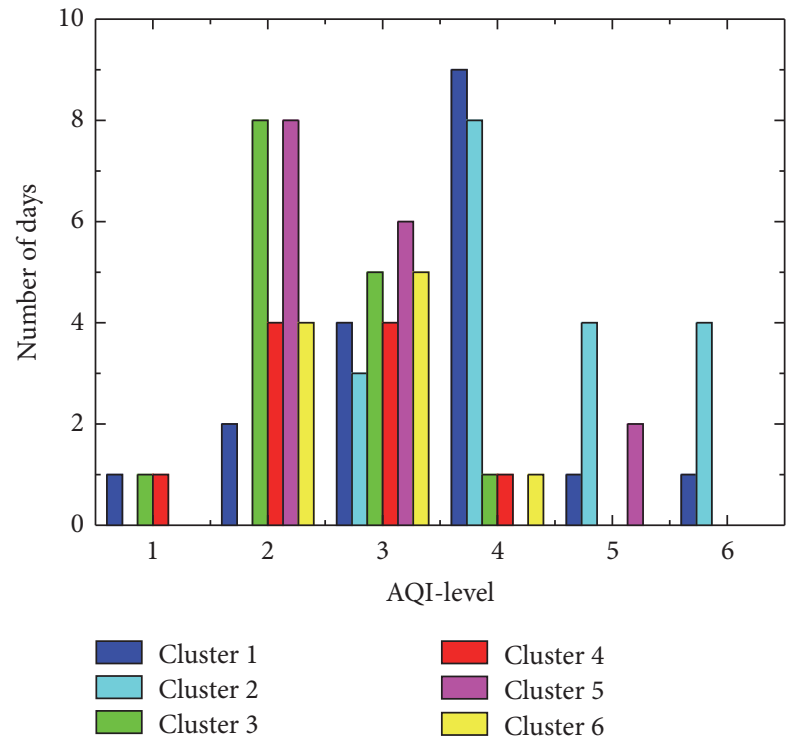

FIGURE 5: Numbers of each cluster observed in per-AQI level from 2013 to 2014 at Beijing site.

of Beijing is much higher than global aerosol types, which is because Beijing usually suffers high concentration of aerosol [9]. The SSAs of three fine particle aerosols of Beijing are $0.95,0.91$, and 0.87 , which is larger than the value of global aerosol, $0.92,0.88$, and 0.8 . Interestingly, all particle volume concentration, SSA, and asymmetry parameter of global dust are larger than polluted dust and smaller than desert dust, which indicates that tow dust aerosol may be more "pure" than dust in global aerosol types.

(2) Comparison with East Asian Aerosol Types. Lee and Kim (2010) performed a cluster analysis for AERONET records of East Asia, which were divided into four fine-mode types (CAT (category) 1 to 4 ) and two coarse-mode types (CAT5 and CAT6) [17]. In addition, the two coarse-modes were referred to as dusty aerosols and the others were considered a mixed type of pollution. Four of the six aerosol types in Beijing show similarities with Lee's in East Asia; they are fine particle nonabsorbing aerosol to CAT2, fine particle highly absorbing aerosol to CAT3, and polluted dust and desert dust to two coarse-modes. Table 4 shows the characteristics of each aerosol type identified by Lee et al. (2010).

Figure 8 displays comparisons of characteristics of four aerosol types between East Asia and Beijing. Figures 8(a) and $8(\mathrm{~g})$ show that fine particle nonabsorbing aerosol of Beijing is stronger in particle scattering and lower in particle volume concentration. But the wavelength dependence of asymmetry parameter demonstrates similarities (Figure 8(d)). The CAT3 in East Asia and fine particle highly absorbing aerosol in Beijing exhibit similar particle size distributions and asymmetry parameter. But the absorption of the latter is much stronger than the former (Figure 8(b)), owing to the fossil fuel combustion in Beijing (see Section 3.2.3). It can be seen from Figures 8(c), 8(f), and 8(i) that the properties of desert dust in Beijing and CAT5 in East Asia are exactly similar to each other. Meanwhile, higher SSAs and particle volume concentration of desert dust compared with CAT6 probably due to sites close to dust source regions (like Yulin selected by Lee et al. (2010)) were not included in this paper. It is interesting to note the pronounced differences between polluted dust in Beijing and CAT5/CAT6 in East Asia, indicating apparently polluted dust, a unique aerosol type.

3.3. Variation of Optical Characteristics with Membership Degrees. The optical properties discussed in Section 3.2 are represented by the center values of each cluster. But the differences between records at edge and near center of cluster are inevitable. Particularly for multiparticles mixture aerosol, only representing the aerosol by the center of cluster will produce large errors. As described in Section 2.2, the membership degree indicates the confidence degree of one record belonging to clusters, which is an optimal parameter to analyze these particles at boundary of multiclusters. Therefore, characteristics of aerosol (optical and microphysical) with different membership degree intervals are investigated here. It should be noted that we focus on the internal variation of optical properties for each aerosol type.

The membership degrees (MD) of six aerosol types are divided into five intervals: $0.17 \leq \mathrm{MD}<0.27,0.27 \leq \mathrm{MD}<$ $0.37,0.37 \leq \mathrm{MD}<0.47,0.47 \leq \mathrm{MD}<0.57$, and $0.57 \leq \mathrm{MD}$. We chose the value of 0.17 because when membership degree of the record to one type is larger than 1/6 (as there are six types), it means that this record may belong to that type. And we take the step of 0.1 to make sure that there is a similar amount of records within each interval. The numbers of records within each interval are listed in Table 5.

Figure 9 shows the AODs of six aerosol types varying with the membership degree and their mean values within each membership degree interval at wavelength of $440 \mathrm{~nm}$. Fine particle nonabsorbing aerosol (cluster 1, Figure 9(a)) and fine-MA1 (cluster 2, Figure 9(b)) show large range of AOD variation (from 0 to 4 ). The large range is reasonable, because both types are frequently observed at polluted days (discussed in Section 3.2). Nevertheless, the other four 


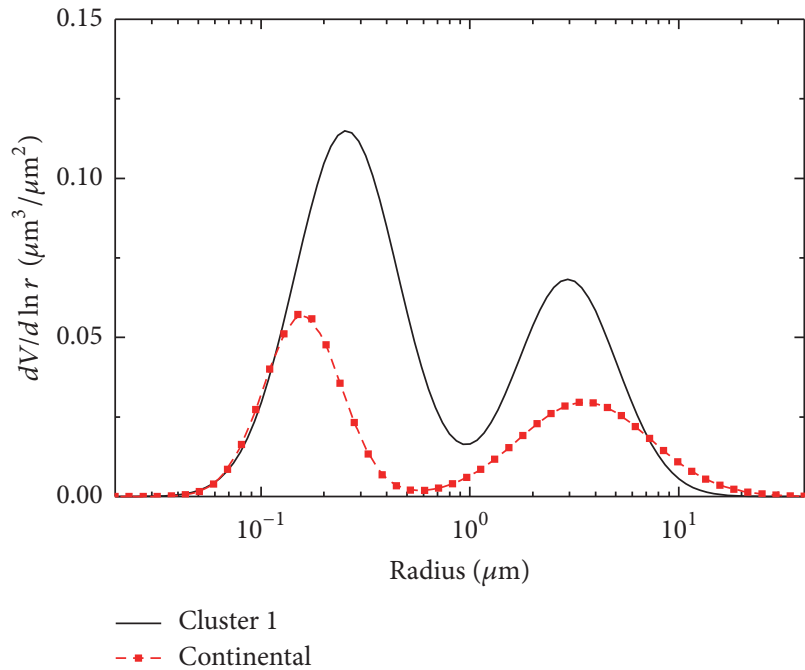

(a)

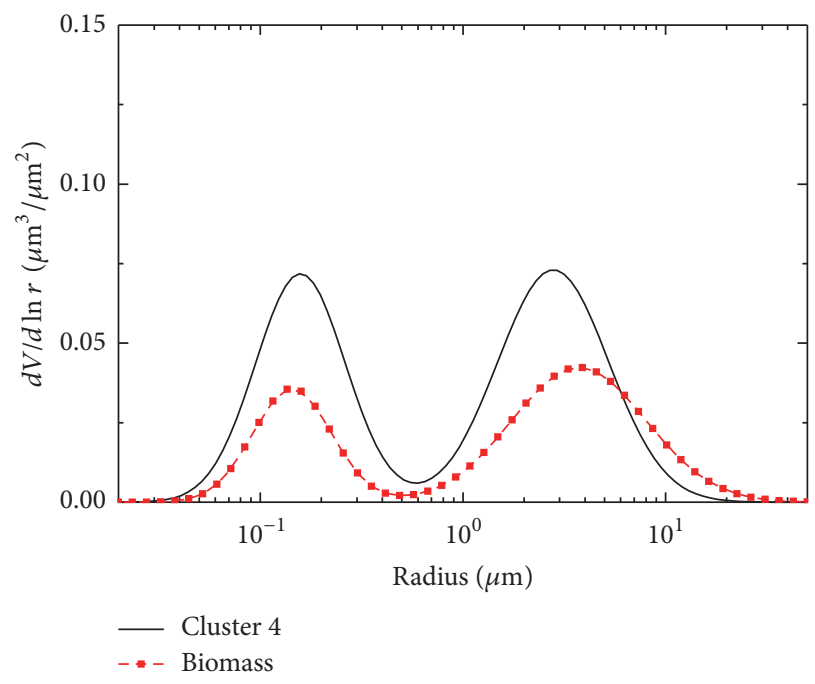

(c)

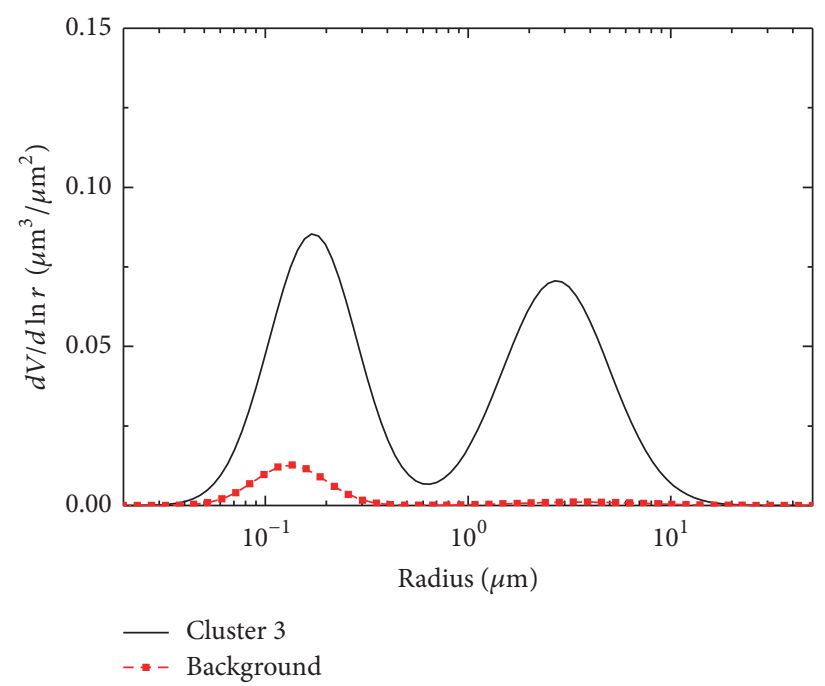

(b)

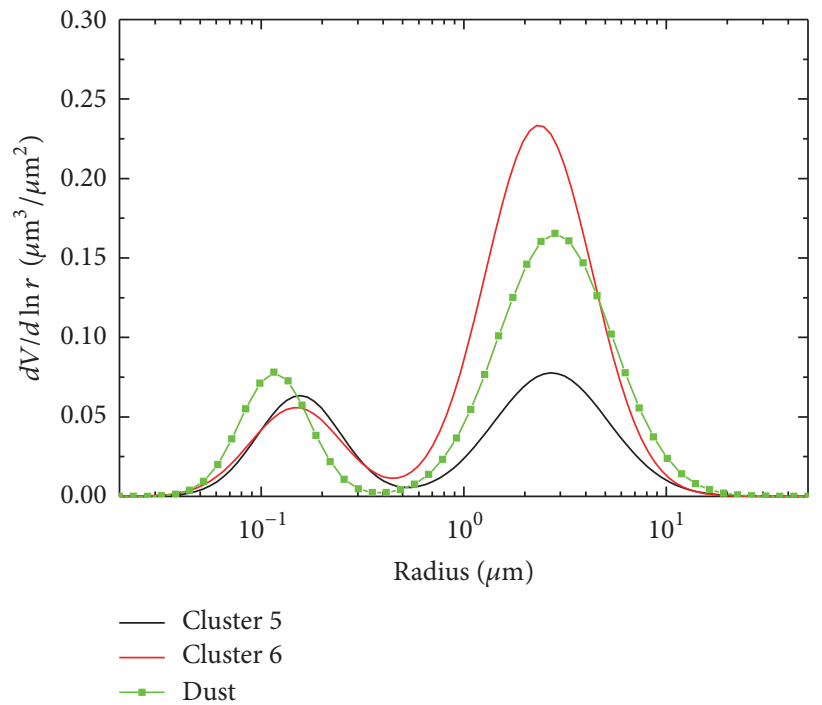

(d)

FIGURE 6: Size distribution comparison with global aerosol types.

aerosol types show relatively smaller variation ranges (from 0 to 2). And there are fewer that occurred during polluted days. Furthermore, the AODs obviously concentrate in the low varying range with increasing membership degree for all aerosol types.

Figure 10 shows the mean values of AOD within the five membership degree intervals at four wavelengths $(440,676$, 869, and $1020 \mathrm{~nm}$ ). Figures $10(\mathrm{a})$ and $10(\mathrm{~b})$ show that the average AODs of fine particle moderately absorbing aerosol for all wavelengths exhibit relatively flat behaviors. However, the other five aerosol types exhibit clearly declination with the increase of the membership degree interval. Moreover, the trends are nearly the same between different wavelengths for each aerosol type.

The SSAs $(440 \mathrm{~nm})$ of six aerosol types varying with membership degree and their mean values within each membership degree interval are plotted in Figure 11. Same as AODs, points of SSA concentrate in the low varying range with increasing membership degree for all aerosol types. It can be seen from Figure 11(a) that the SSAs of fine particle nonabsorbing aerosol (cluster 1 ) fall within the range between 0.9 and 1.0. This characteristic is consistent with the nonabsorbing aerosol (strong scattering) of cluster 1. Besides, it is interesting to find that there are some strongly absorbing particles (SSA $<0.8$ ) at membership degrees between 0.27 and 0.47 in Figure 11(d) (cluster 4). As discussed in Section 3.2.3, these particles are probably the black carbon, which are frequently observed in Beijing with high absorption [23, 28].

The mean values of SSA within the five membership degree intervals at four wavelengths $(440,676,869$, and $1020 \mathrm{~nm}$ ) are plotted in Figure 12. Means of SSA show clear descending trend in Figure 12(a), which indicates that with the increase of membership degree scattering ability of 


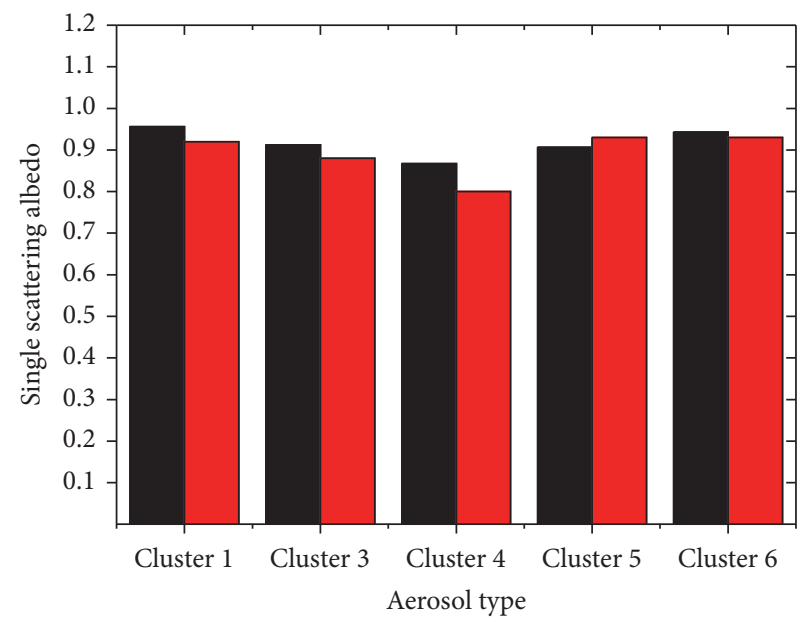

This paper Omar et al.

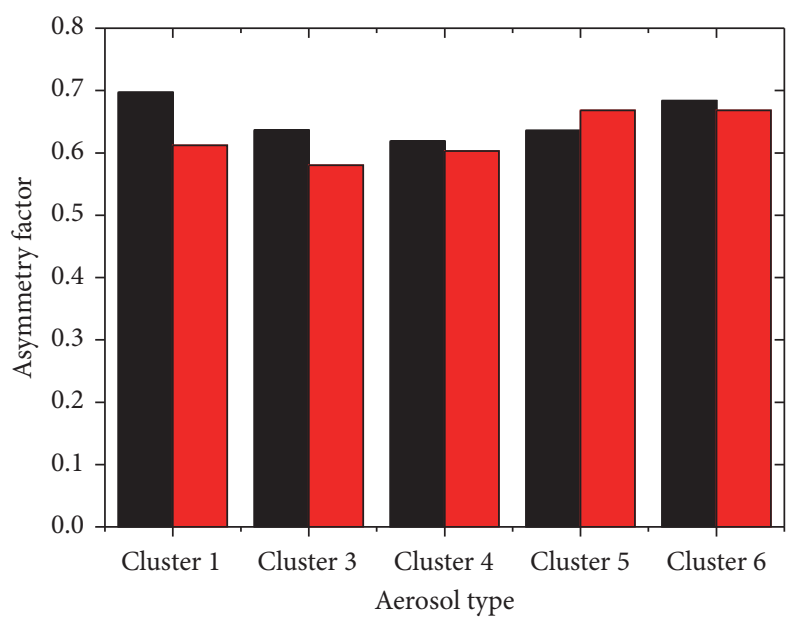

This paper Omar et al.

FIGURE 7: SSA and ASYM comparison with global aerosol types.

TABle 4: Characteristics of East Asian aerosol types by Lee et al. (2010).

\begin{tabular}{|c|c|c|c|c|c|c|c|}
\hline & & $\mathrm{CAT}^{1}{ }^{1}$ & CAT2 & CAT3 & CAT4 & CAT5 & CAT6 \\
\hline \multirow{4}{*}{ SSA } & $440 \mathrm{~nm}$ & 0.915 & 0.927 & 0.904 & 0.908 & 0.893 & 0.900 \\
\hline & $676 \mathrm{~nm}$ & 0.927 & 0.941 & 0.908 & 0.914 & 0.939 & 0.957 \\
\hline & $869 \mathrm{~nm}$ & 0.918 & 0.933 & 0.897 & 0.907 & 0.945 & 0.964 \\
\hline & $1020 \mathrm{~nm}$ & 0.912 & 0.928 & 0.889 & 0.903 & 0.948 & 0.966 \\
\hline \multirow{4}{*}{ REFR } & $440 \mathrm{~nm}$ & 1.468 & 1.478 & 1.441 & 1.454 & 1.508 & 1.549 \\
\hline & $676 \mathrm{~nm}$ & 1.480 & 1.483 & 1.458 & 1.472 & 1.535 & 1.549 \\
\hline & $869 \mathrm{~nm}$ & 1.485 & 1.483 & 1.468 & 1.482 & 1.536 & 1.537 \\
\hline & $1020 \mathrm{~nm}$ & 1.481 & 1.476 & 1.468 & 1.481 & 1.528 & 1.525 \\
\hline \multirow{4}{*}{ REFI } & $440 \mathrm{~nm}$ & 0.0119 & 0.0099 & 0.0127 & 0.0112 & 0.007 & 0.0049 \\
\hline & $676 \mathrm{~nm}$ & 0.0086 & 0.0074 & 0.01 & 0.0088 & 0.0037 & 0.0024 \\
\hline & $869 \mathrm{~nm}$ & 0.0088 & 0.0078 & 0.0102 & 0.009 & 0.0036 & 0.0023 \\
\hline & $1020 \mathrm{~nm}$ & 0.0091 & 0.008 & 0.0104 & 0.0092 & 0.0036 & 0.0025 \\
\hline \multirow{4}{*}{ ASYM } & $440 \mathrm{~nm}$ & 0.721 & 0.729 & 0.716 & 0.713 & 0.73 & 0.748 \\
\hline & $676 \mathrm{~nm}$ & 0.664 & 0.685 & 0.654 & 0.655 & 0.693 & 0.714 \\
\hline & $869 \mathrm{~nm}$ & 0.636 & 0.657 & 0.626 & 0.635 & 0.691 & 0.707 \\
\hline & $1020 \mathrm{~nm}$ & 0.626 & 0.643 & 0.618 & 0.634 & 0.696 & 0.707 \\
\hline
\end{tabular}

${ }^{1}$ CAT: category.

fine particle nonabsorbing aerosol (cluster 1) is enhancing. This characteristic confirms that the higher the membership degree, the purer the nonabsorbing aerosol. Figures 12(b) and 12(c) show the mean values of SSA obviously descending when membership degree increases from MDI1 to MDI2. However, the changes are hardly observed when membership degree interval increases from MDI2 to MDI5. These characteristics demonstrate that records at the edge of cluster 2 (fine-M1) and cluster 3 (fine-M2) have stronger scattering (or lower absorbing) than those near center. Figure 12(d) exhibits clearly ascending trend of SSA means, which is a manifestation of the reasonability to identify cluster 4 as highly absorbing aerosol. The ascending trend also indicates that the higher membership degree denotes the purer highly absorbing aerosol.
Figures 12(e) and 12(f) show some similarities between polluted dust and desert dust at wavelengths of $440 \mathrm{~nm}$. Firstly, mean values of SSA slightly decrease with the increase of membership degree interval. Furthermore, mean values of SSA at $440 \mathrm{~nm}$ are obviously lower than other wavelengths. As discussed in Sections 3.2.4 and 3.2.5, these SSA trends agree well with the relationships between SSA and dust compositions, which certify our identification that both cluster 5 (polluted dust) and cluster 6 (desert dust) are dust-related aerosols. However, there are some differences between two clusters. SSAs at $440 \mathrm{~nm}$ are distinctly smaller than at other wavelengths. Besides, Figures 12(e) and 12(f) show different trends at wavelengths longer than $440 \mathrm{~nm}$; the former displays descending trend while the latter shows no clear variation. These differences can be attributed to cluster 


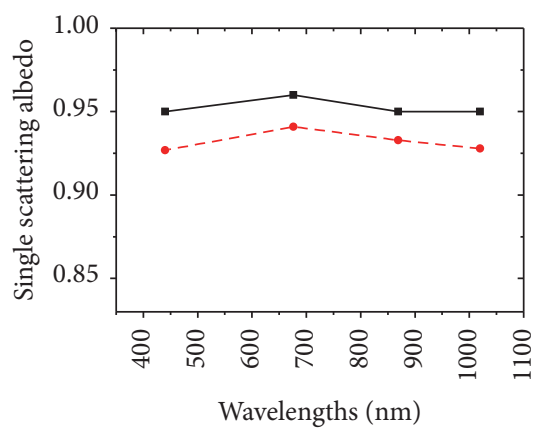

$\rightarrow$ This paper cluster 1

_ - Lee et al. CAT2

(a)

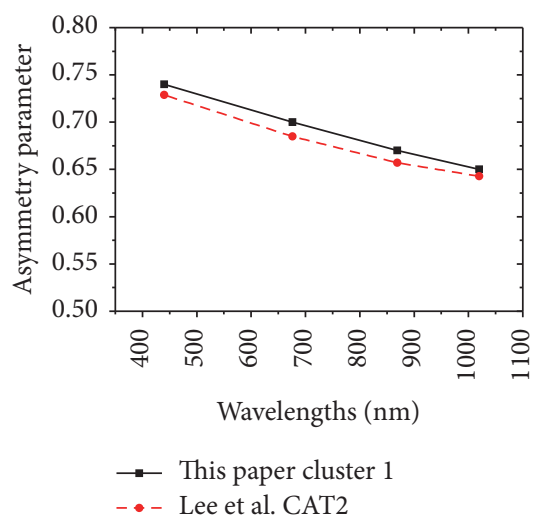

(d)

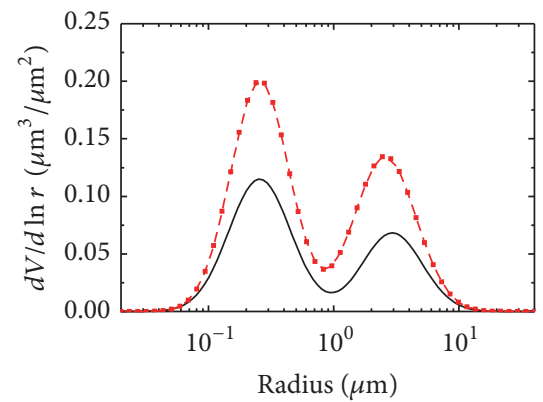

_ This paper cluster 1

- - Lee et al. CAT2

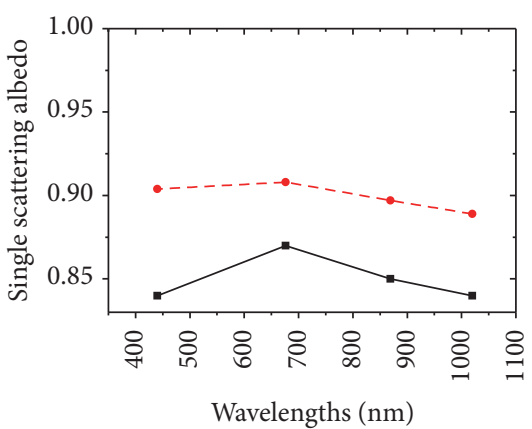

$\rightarrow$ This paper cluster 4

_- Lee et al. CAT3

(b)

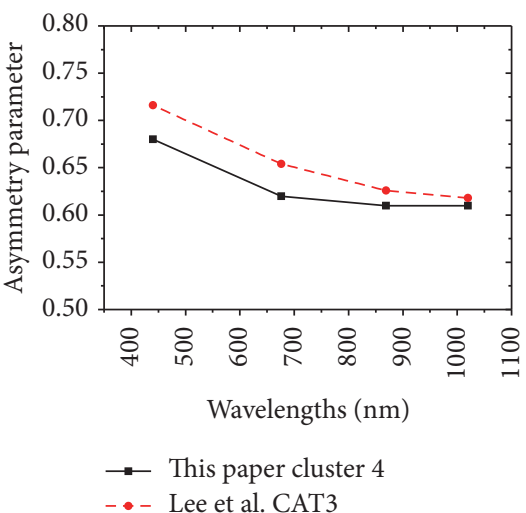

(e)

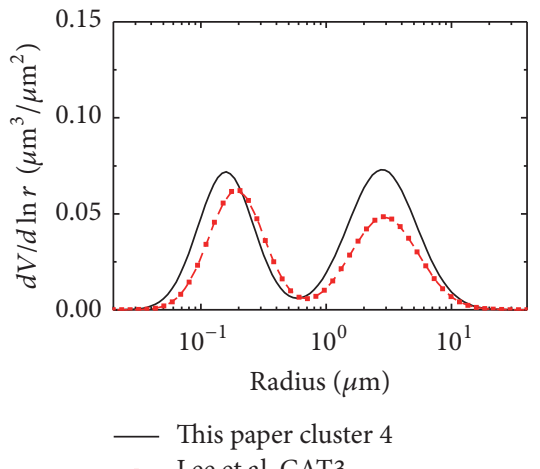

(h)

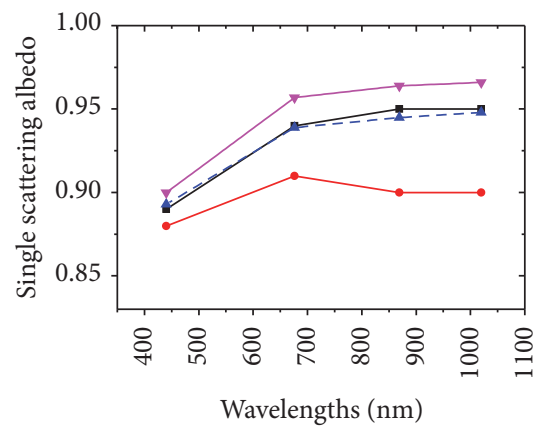

Wavelengths (nm)

$\rightarrow$ This paper $\quad-\$$ - Lee et al. cluster $5 \quad$ CAT5

$\rightarrow$ This paper $\quad-₹-$ Lee et al. cluster $6 \quad$ CAT6

(c)

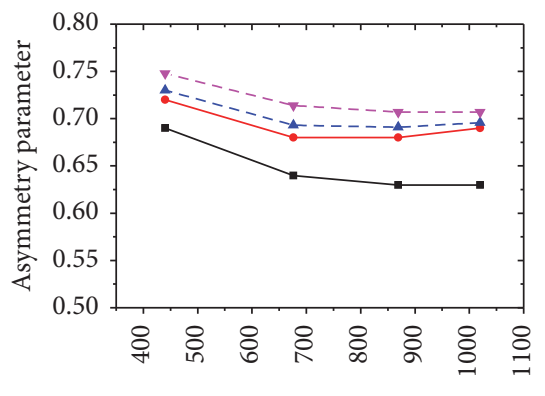

Wavelengths (nm)

- This paper $\quad-\quad-$ Lee et al cluster $5 \quad$ CAT5

- This paper $\quad-$ - Lee et al. cluster $6 \quad$ CAT6

(f)

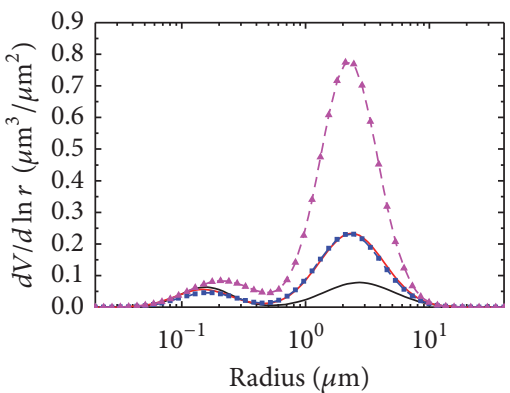

$\begin{array}{lrl}\text { This paper } & \cdots & \text { Lee et al. } \\ \text { cluster } 5 & & \text { CAT5 } \\ \text { This paper } & -\neq- & \text { Lee et al. } \\ \text { cluster } 6 & & \text { CAT6 }\end{array}$

(i)

Figure 8: Comparison with East Asian aerosol types.

TABLE 5: The record numbers within each membership degree interval.

\begin{tabular}{|c|c|c|c|c|c|c|}
\hline Membership degree intervals (MDI) & $\mathrm{C} 1^{1}$ & $\mathrm{C} 2$ & $\mathrm{C} 3$ & $\mathrm{C} 4$ & C5 & C6 \\
\hline MDI1: $0.17 \leq \mathrm{MD}^{2}<0.27$ & 156 & 131 & 60 & 117 & 43 & 86 \\
\hline MDI2: $0.27 \leq \mathrm{MD}<0.37$ & 508 & 569 & 298 & 603 & 404 & 308 \\
\hline MDI3: $0.37 \leq \mathrm{MD}<0.47$ & 305 & 326 & 240 & 456 & 413 & 234 \\
\hline MDI4: $0.47 \leq \mathrm{MD}<0.57$ & 115 & 128 & 197 & 181 & 275 & 153 \\
\hline MDI5: $0.57 \leq \mathrm{MD}$ & 40 & 34 & 122 & 37 & 117 & 76 \\
\hline
\end{tabular}

${ }^{1} \mathrm{C}$ : cluster. ${ }^{2} \mathrm{MD}$ : membership degree. 


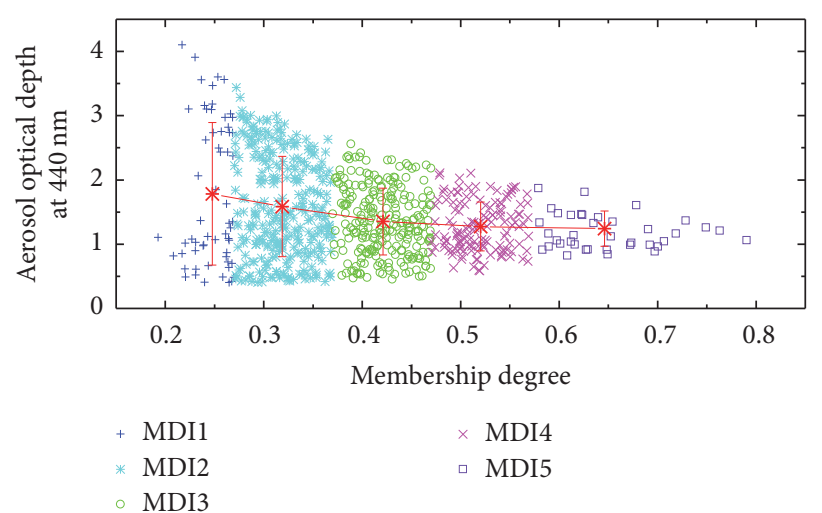

(a) Cluster 1

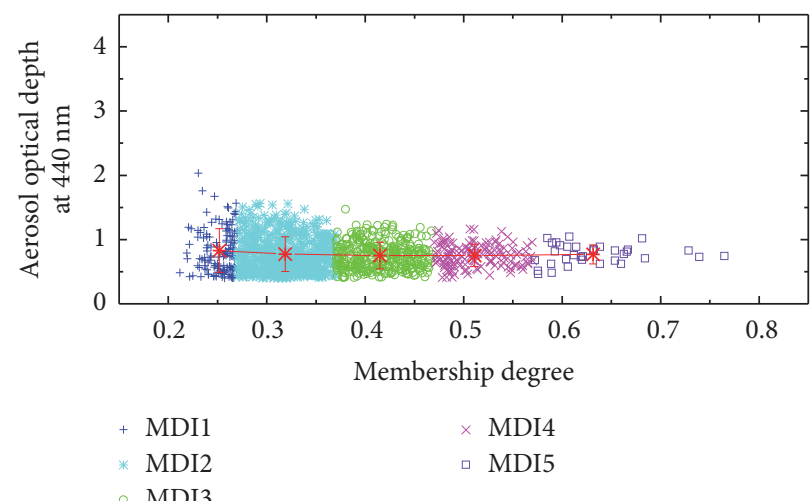

(c) Cluster 3

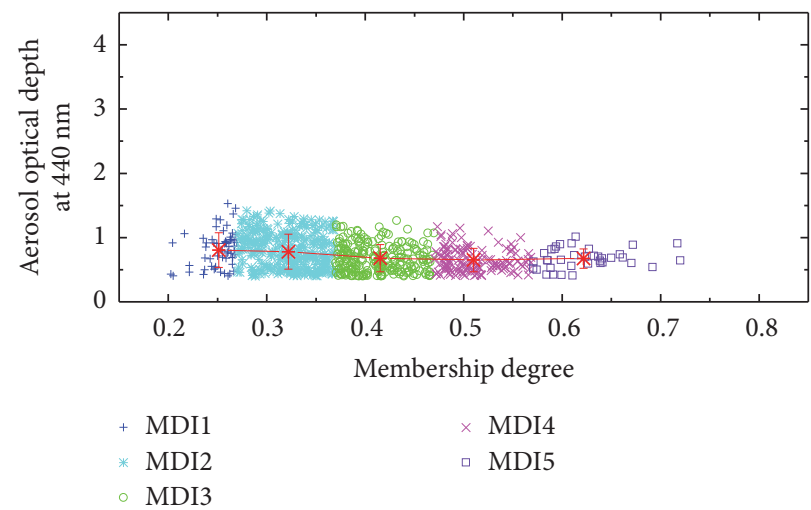

(e) Cluster 5

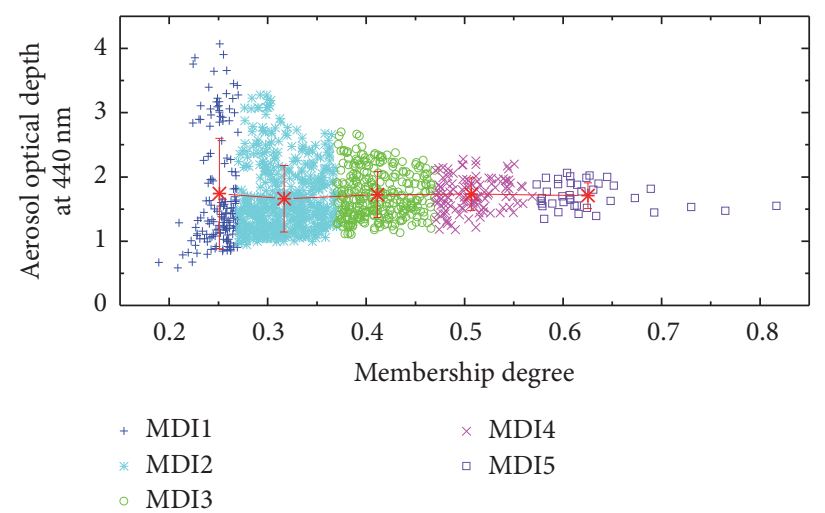

(b) Cluster 2

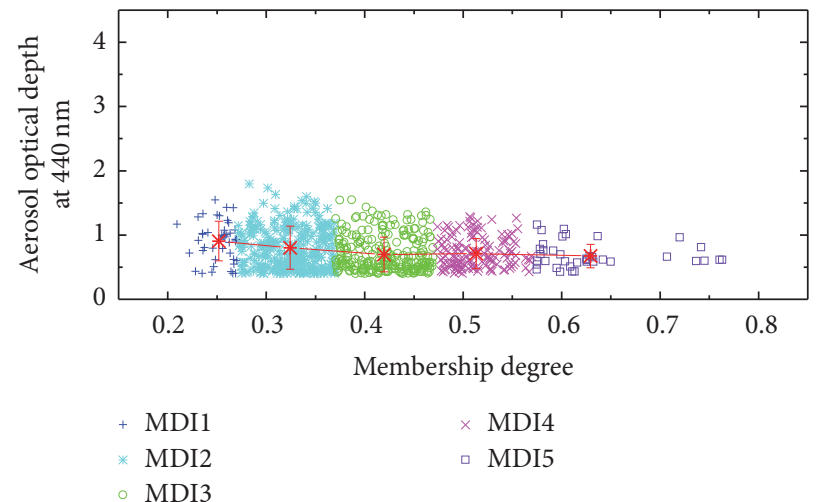

(d) Cluster 4

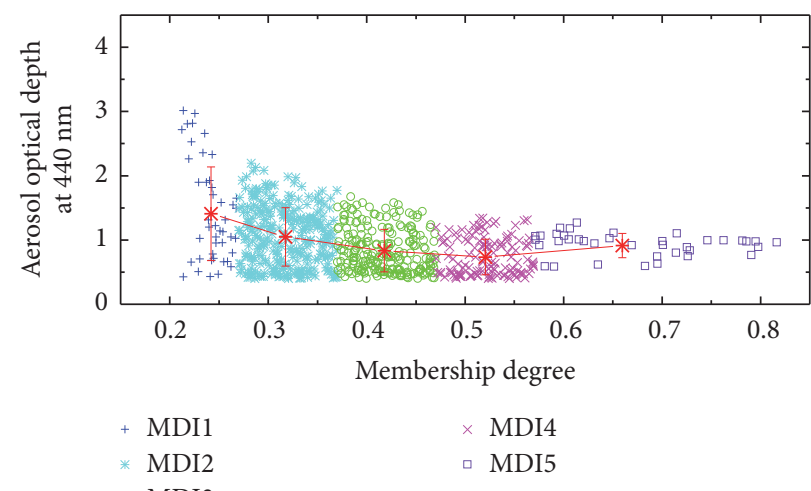

(f) Cluster 6

FIGURE 9: AODs at $440 \mathrm{~nm}$ with membership degrees: asterisk represents mean value of AOD in each interval, and the vertical bars represent the standard deviation.

5 (polluted dust) containing absorbing anthropogenic aerosol (such as black carbon), while cluster 6 is dominated only by dust. These characteristics validate that it is reasonable to identify cluster 5 as polluted dust and cluster 6 as desert dust.

Figure 13 is scatterplot of sphericity parameter versus membership degree for six aerosol types. Figures 13(a), 13(b), 13(c), and 13(d) show high variation of sphericity parameters, which indicates that the first four aerosol types show no correlation between sphericity parameters and membership degree. However, Figure 13(e) exhibits clearly descending trends and all mean values of sphericity parameter are lower than 40. Moreover, records in Figure 13(f) are more concentrated with $95 \%$ of them falling below 20 . These indicate that both cluster 5 and cluster 6 are close to nonsphericity. Because most dust types are nonsphericity particles [35], these analyses again confirm our identification of polluted dust (cluster 5) and desert dust (cluster 6).

The above analyses confirm reasonability of our results of clustering and identification of aerosol types. Moreover, the internal variation of optical properties of aerosol type can be well investigated with the help of membership degree interval (MDI). 


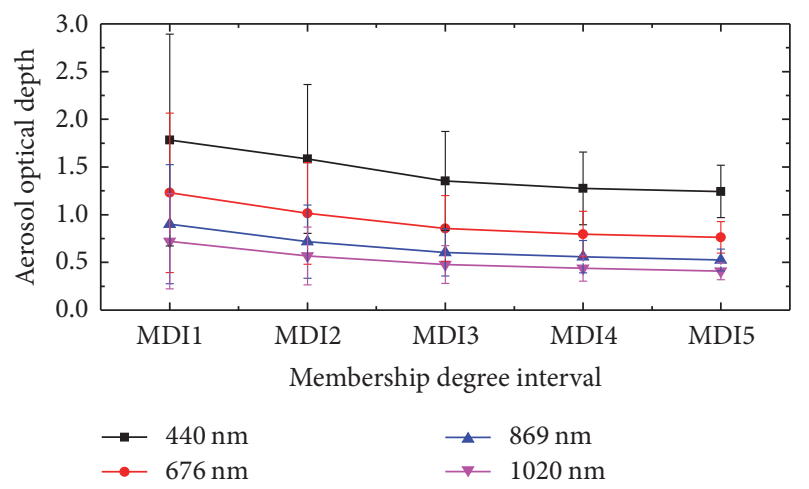

(a) Cluster 1

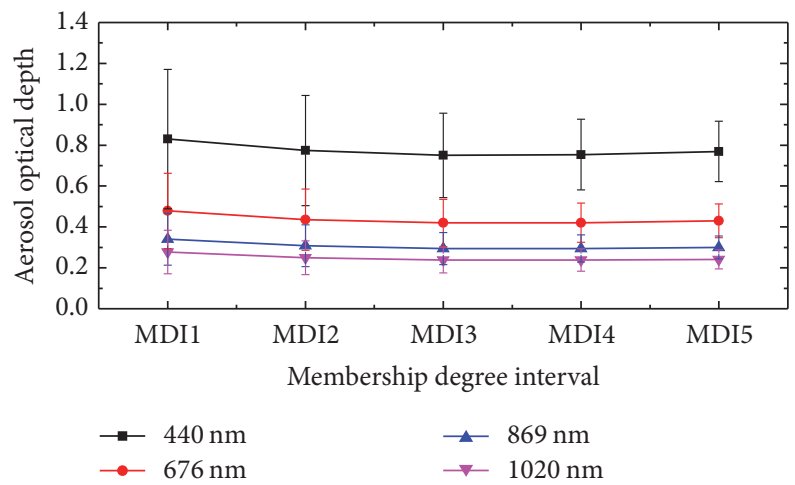

(c) Cluster 3

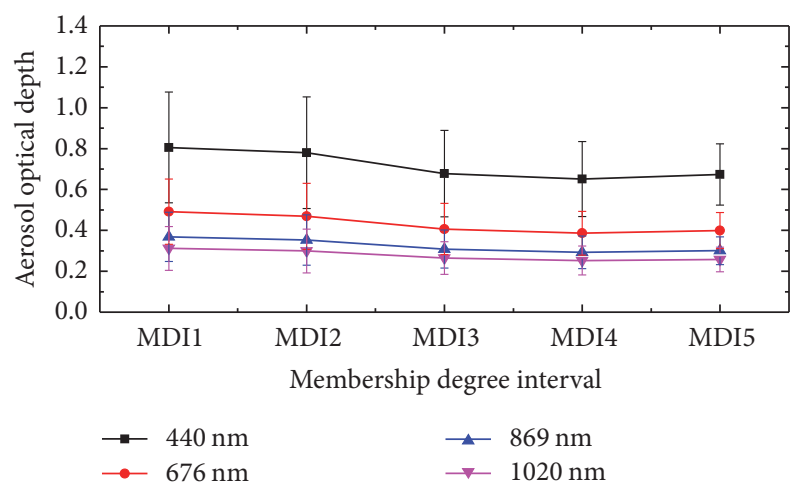

(e) Cluster 5

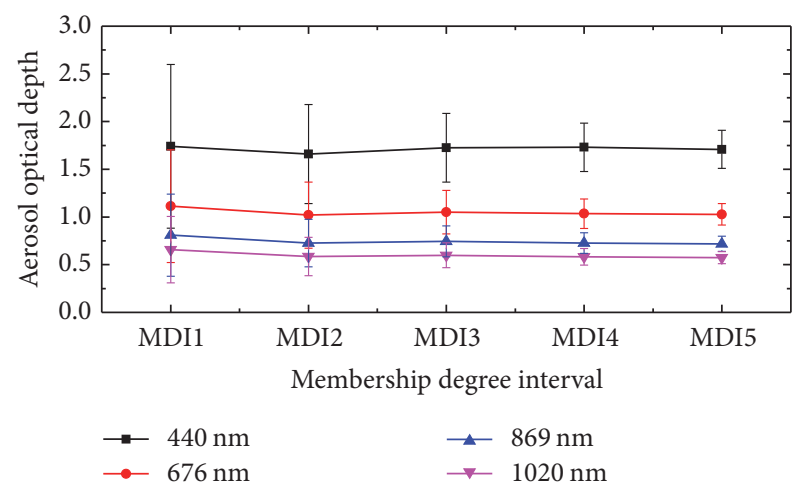

(b) Cluster 2

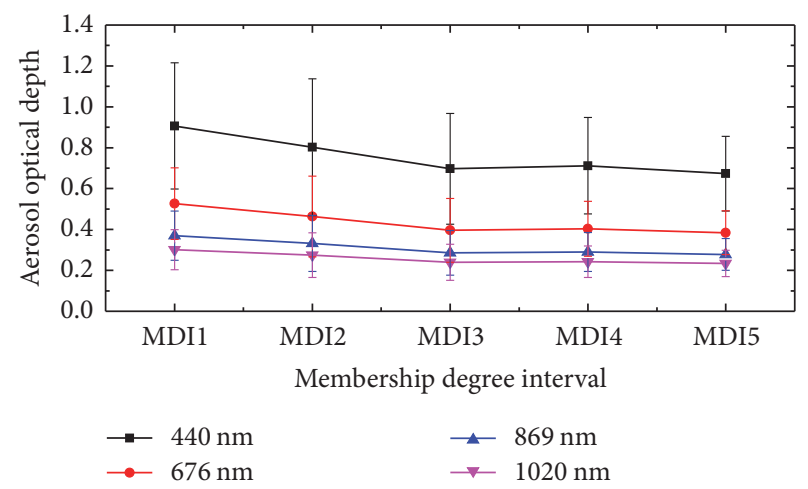

(d) Cluster 4

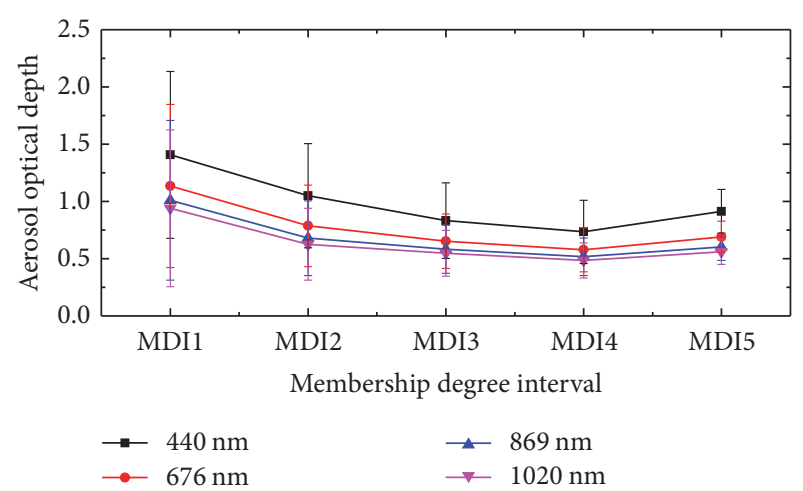

(f) Cluster 6

FIGURE 10: Variation of AODs with membership degree intervals at four wavelengths: the vertical bars represent the standard deviation.

3.4. Seasonal Variation of Aerosol Types. The seasonal variations of aerosol types over Beijing are investigated in this section. Figure 14 shows the monthly distributions of six aerosol types during 2001-2014 in Beijing. It can be seen from Figure 14 that the fine particle nonabsorbing aerosol (cluster 1 ) is mostly observed from June to September (65\% of total number). These four months generally experience the largest atmospheric humidity in Beijing. Due to highly relative humidity condition, the growth aerosol hygroscopicity could result in increasing of scattering [33]. This is consistent with the fact that fine particle nonabsorbing aerosol shows largest water vapor (Figure 2(d)).

Fine-MA1 is hardly observed from July to September while in other months it is of frequent occurrence. The fine-MA2 generally occurs throughout the year. As discussed in Section 3.2.2, fine-MA2 is likely the background aerosol; therefore, the similar monthly frequency of incidence is reasonable. The fine particle highly absorbing aerosol is with the greatest frequency of occurrence in winter (November to January). As discussed in Section 3.2.3, this type of aerosol may be attributed to burning of coal in winter for heating supply over north China.

Polluted dust and desert dust both are frequently detected during spring (March to May). In spring, Beijing is generally affected by Gobi Desert. When transported dust mixes with anthropogenic aerosol, it exhibits characteristics of polluted dust. On the contrary, when there is low-level or no mixture with anthropogenic particle, it will exhibit characteristics of desert dust. 


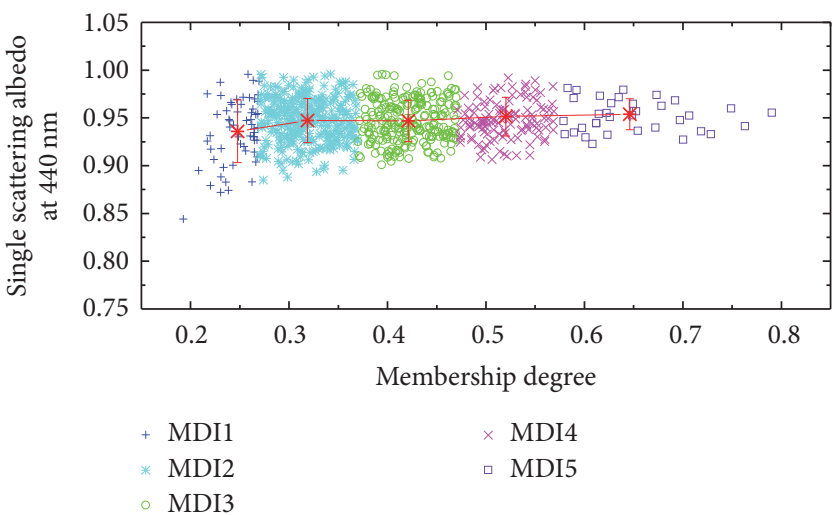

(a) Cluster 1

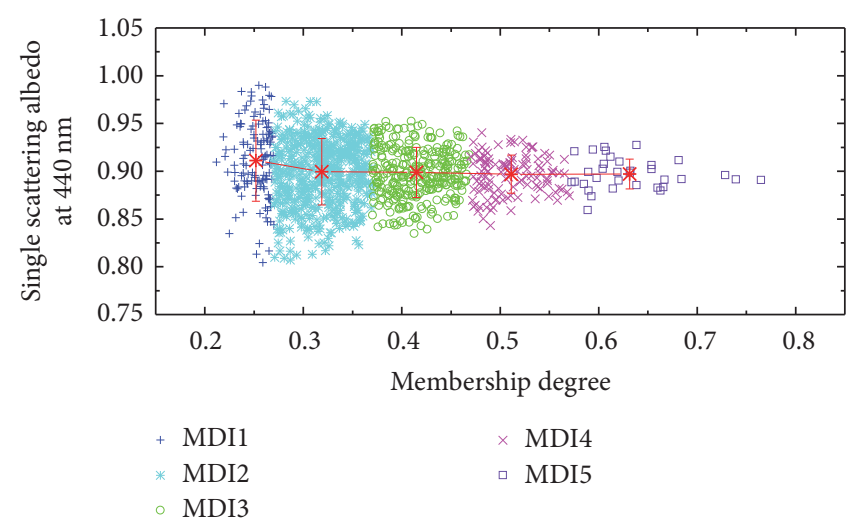

(c) Cluster 3

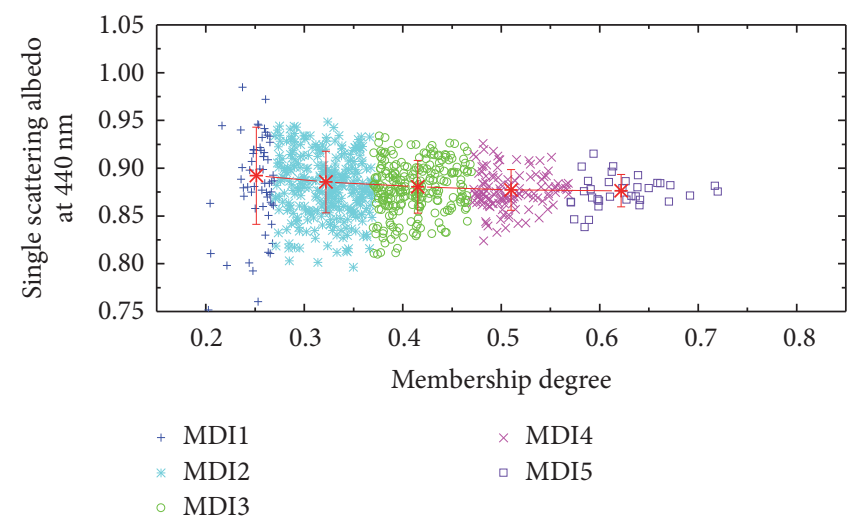

(e) Cluster 5

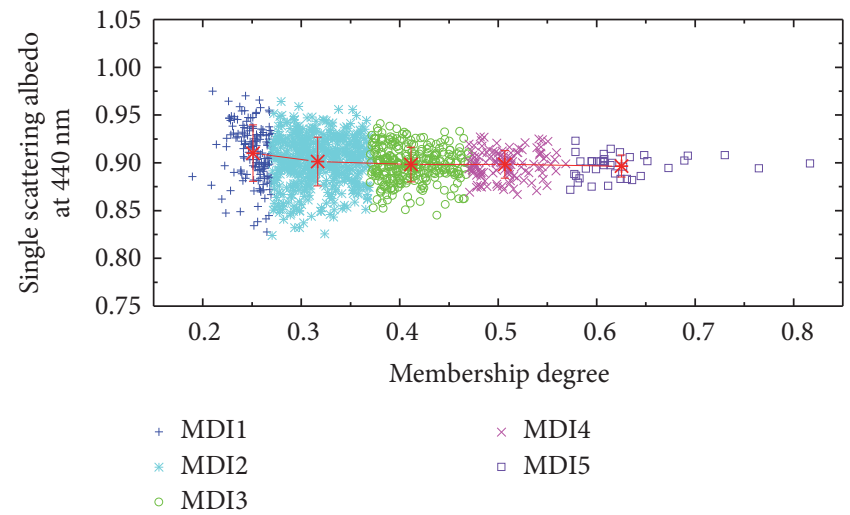

(b) Cluster 2

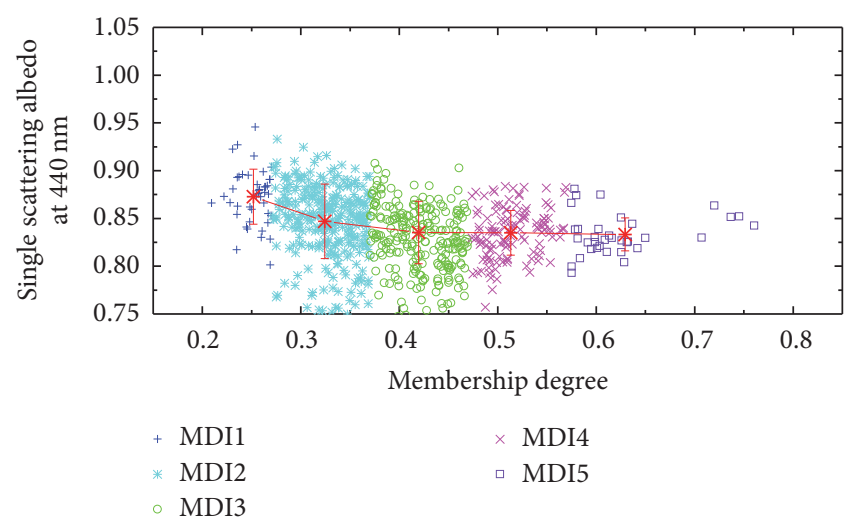

(d) Cluster 4

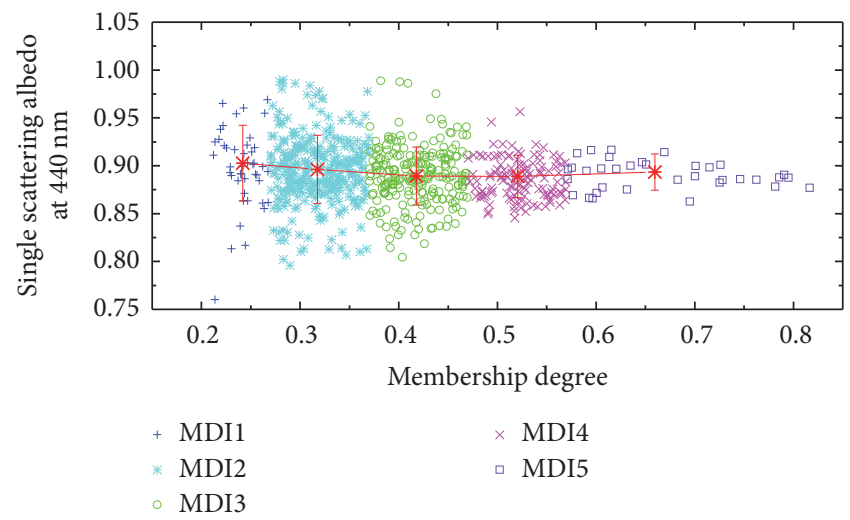

(f) Cluster 6

FIGURE 11: Same as Figure 9 but for SSAs at $440 \mathrm{~nm}$.

Consequently, Beijing is affected by various aerosol types in different seasons. The dominant aerosol types are polluted dust and desert dust in spring, fine particle nonabsorbing aerosol in summer, and fine particle highly absorbing aerosol in winter. The fine particle moderately absorbing aerosols can be observed throughout the year.

\section{Conclusions}

In Beijing, the dominant aerosol types and their characteristics are still unclear. In this paper, we conduct a fuzzy cluster analysis based on fourteen-year (2001-2014) AERONET data set to obtain dominant aerosol types in Beijing. Fuzzy $c$-mean algorithm is applied to classify a total of 6732 records into six aerosol types: fine particle nonabsorbing, two kinds of fine particle moderately absorbing (fine-MAl and fineMA2), fine particle highly absorbing, polluted dust, and dust aerosol. Following the clustering, detailed properties within different membership degree intervals (MDI) are analyzed. Meanwhile, temporal variations of aerosol types are also investigated. The main findings can be summarized as follows:

(1) There are large variations of optical characteristics between different aerosol types in Beijing. Fine particle nonabsorbing aerosol exhibits high fine 


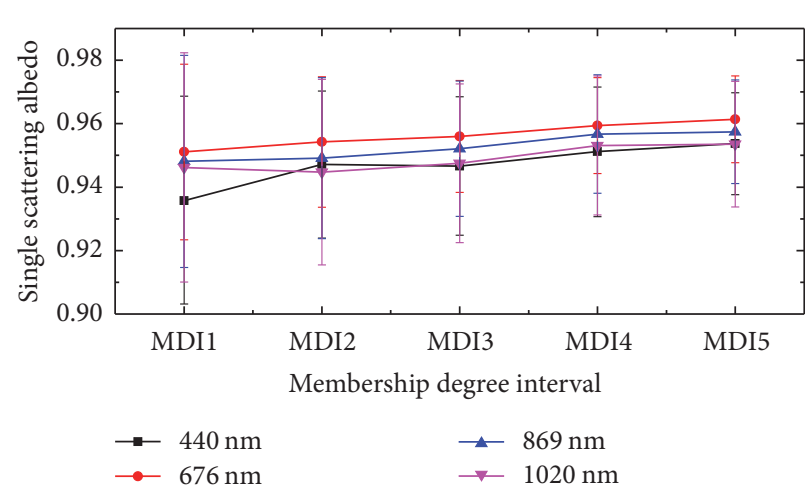

(a) Cluster 1

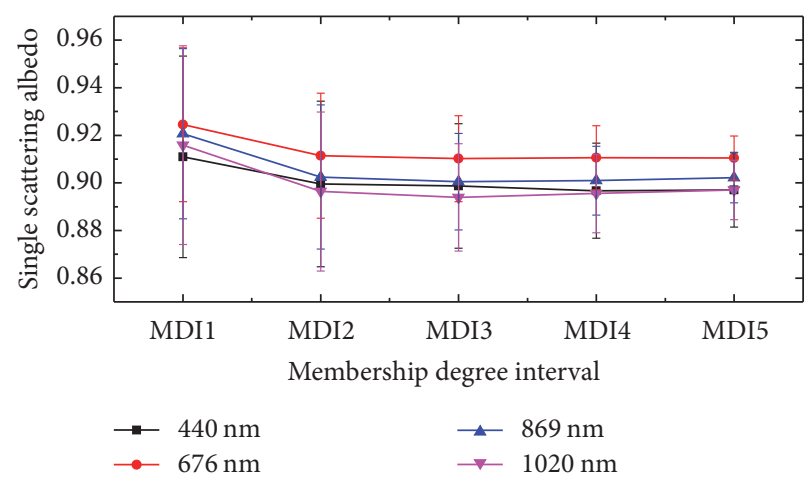

(c) Cluster 3

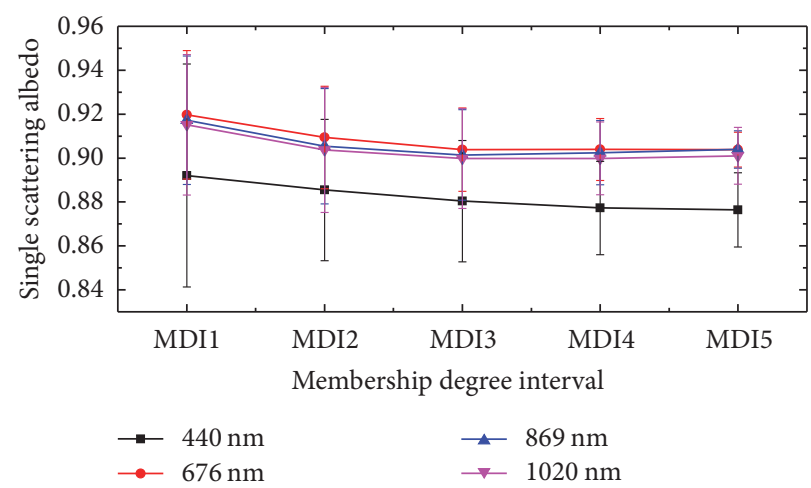

(e) Cluster 5

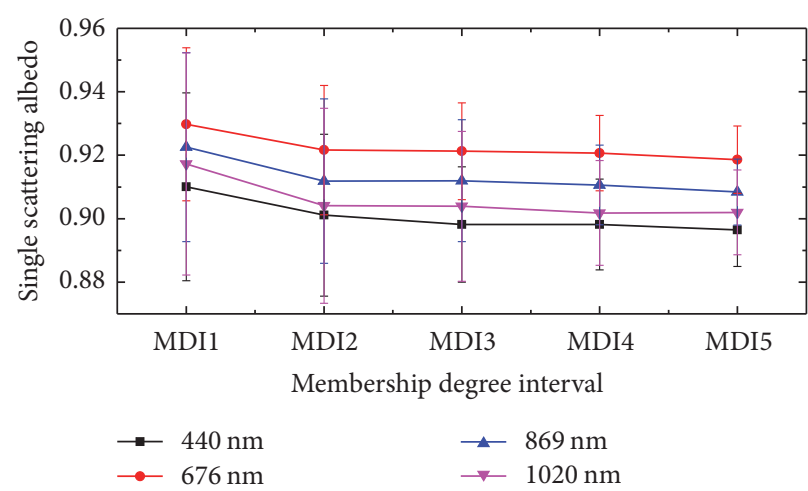

(b) Cluster 2

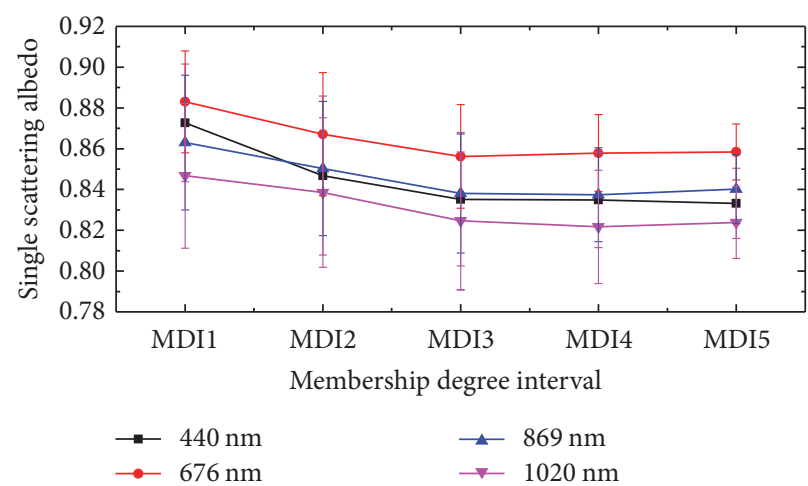

(d) Cluster 4

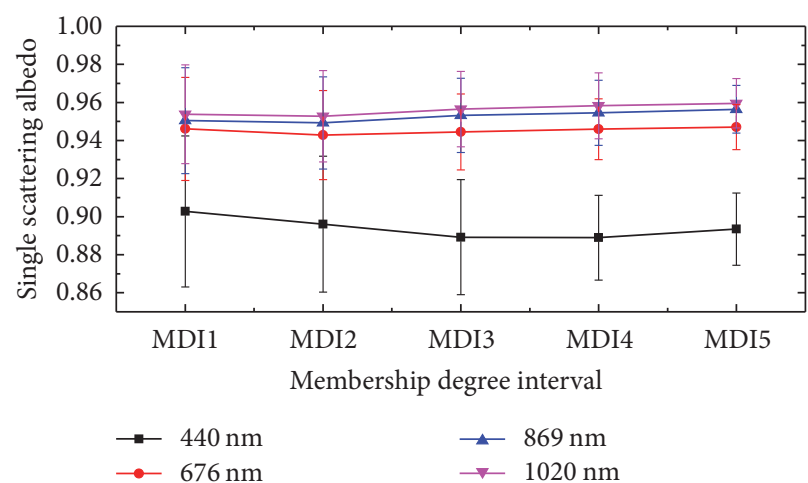

(f) Cluster 6

FIgURE 12: Same as Figure 10 but for SSAs.

fraction by volume (0.64) and strong scattering property; the SSA at $440 \mathrm{~nm}$ is 0.95 . Two kinds of fine particle moderately absorbing aerosols (fine-MA1 and fine-MA2) perform moderate absorption. The SSAs at $440 \mathrm{~nm}$ both are 0.90 . Fine particle highly absorbing aerosol displays strong absorbability; the SSA at $440 \mathrm{~nm}$ is 0.84 . The polluted dust aerosol is for the first time classified as a unique type by cluster analysis method and its SSA at $440 \mathrm{~nm}$ is 0.88 . Desert dust is dominated by nonspherical coarse particles; the SSAs at four selected wavelengths $(440,676,869$, and $1,020 \mathrm{~nm}$ ) are $0.89,0.94,0.95$, and 0.95 . Furthermore, the results indicate that fuzzy clustering is capable of identifying aerosol types in regions where aerosol particles are contributed by complex components.

(2) The optical properties of six aerosol types exhibit different internal variations. These variations can be well investigated with the help of membership degree interval (MDI).

(3) Aerosol types of Beijing display clearly seasonal variation. The dominant aerosol types are polluted dust and desert dust in spring, fine particle nonabsorbing aerosol in summer, and fine particle highly absorbing aerosol in winter. The fine particle moderately absorbing aerosol can be observed throughout the year. 


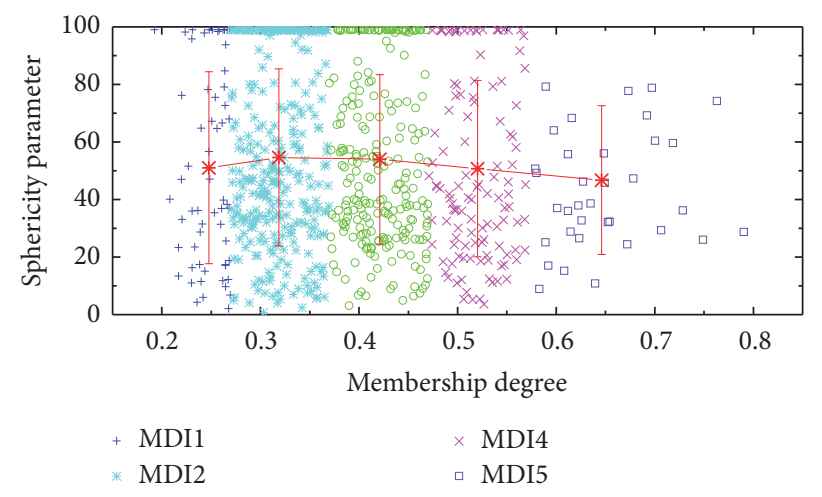

(a) Cluster 1

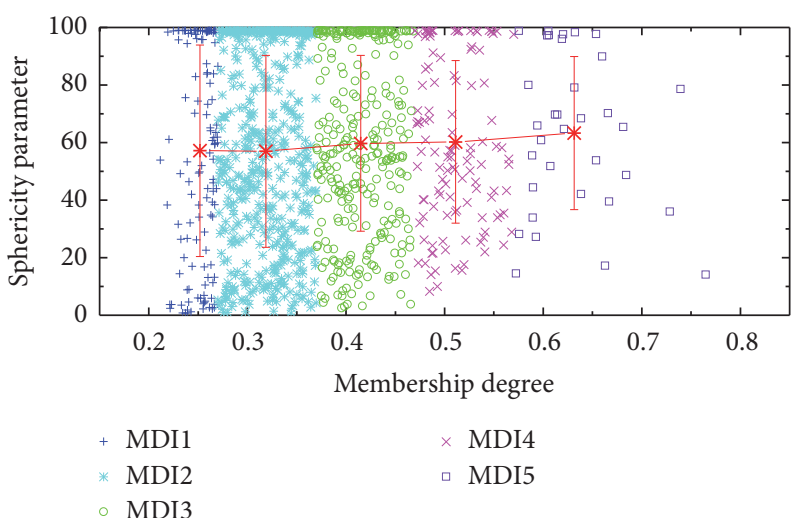

(c) Cluster 3

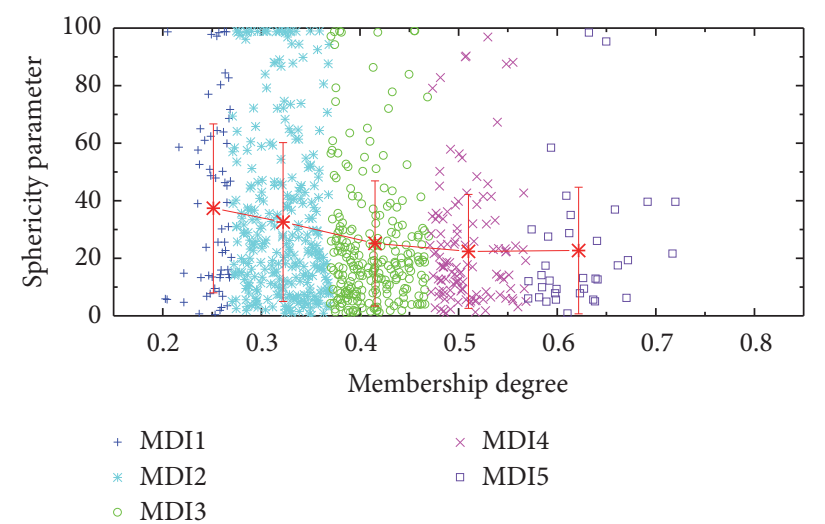

(e) Cluster 5

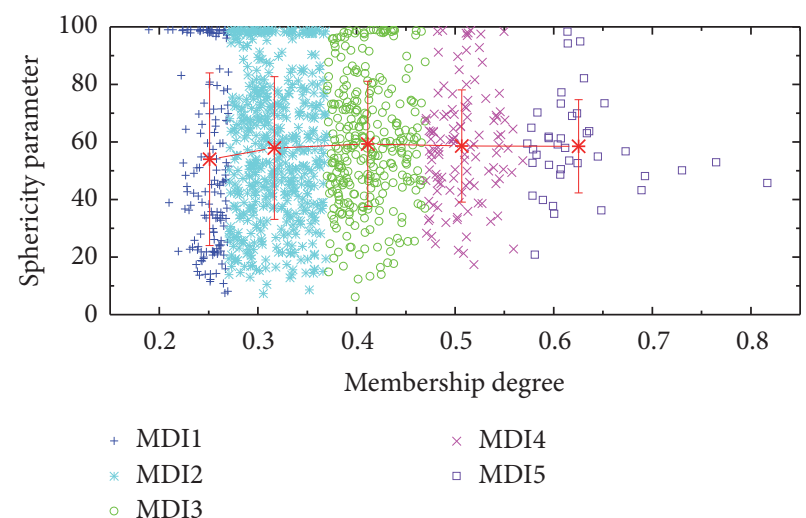

(b) Cluster 2

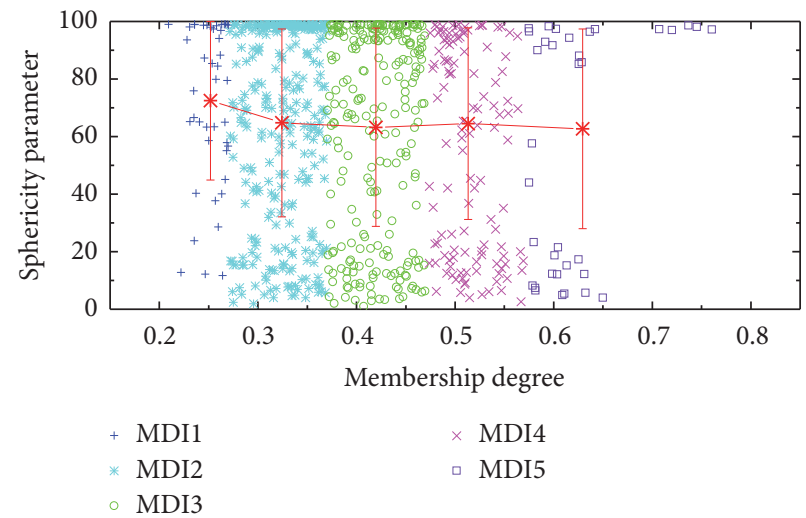

(d) Cluster 4

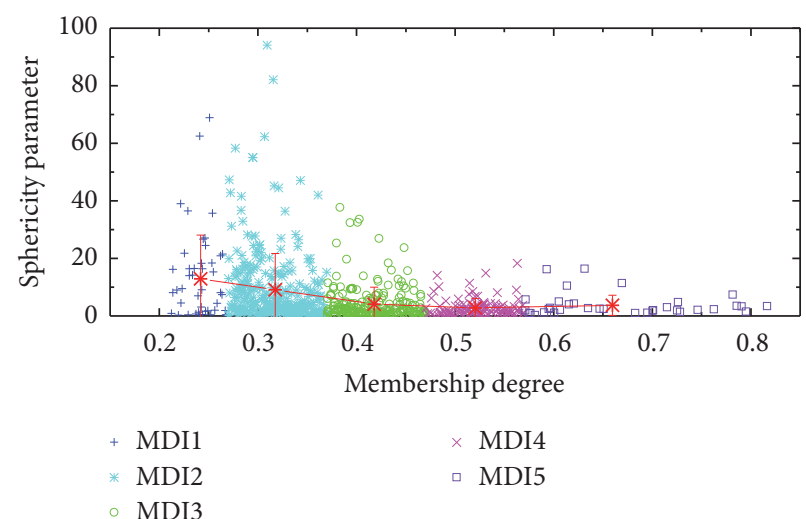

(f) Cluster 6

FIGURE 13: Scatterplots between sphericity parameter and membership degree.

\section{Conflicts of Interest}

The authors declare that there are no conflicts of interest regarding the publication of this paper.

\section{Authors' Contributions}

All authors assisted in analyzing and editing of the paper. Wenhao Zhang is the main author who processed the data, analyzed the results, and wrote the manuscript.

\section{Acknowledgments}

This study was supported by National Natural Science Foundation of China (Grants 41401422 and 41501404), the China High Resolution Earth Observation Project (no. Y6D0060038), the Major State Basic Research Development Program of China (no. Y070070070), the Civil Space PreResearch Project in 13th Five-Year Plan (no. Y7K00100KJ), and the Innovative Projects of Institute of Remote Sensing and Digital Earth Chinese Academy of Sciences (no. Y7SG0600CX). The AERONET data are downloaded from 


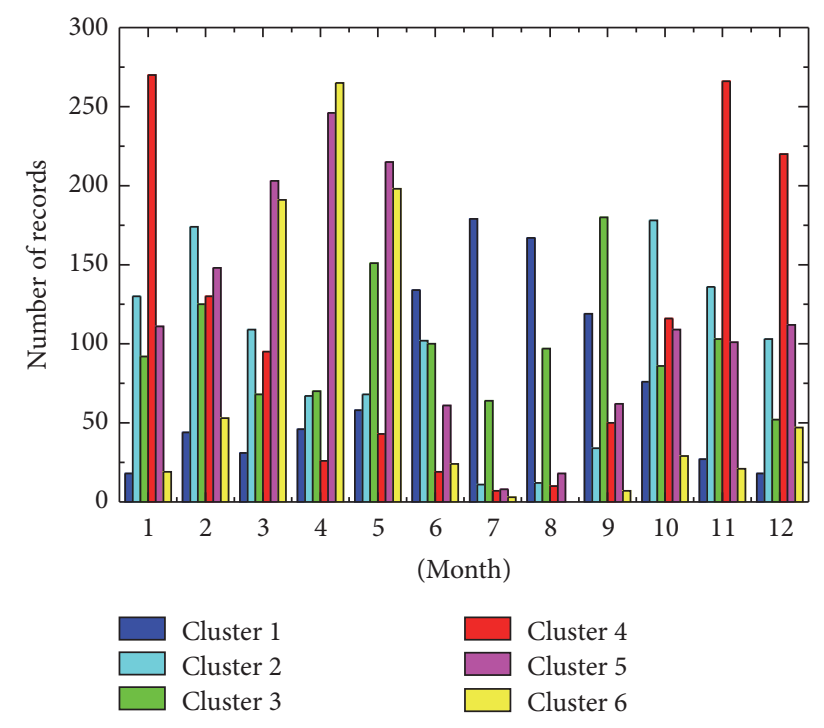

FIGURE 14: The monthly distributions for six clusters (2001-2014).

http://aeronet.gsfc.nasa.gov/. The authors acknowledge all the AERONET investigators for maintaining CIMEL instruments and providing high quality aerosol products.

\section{References}

[1] Y. J. Kaufman, D. Tanré, and O. Boucher, "A satellite view of aerosols in the climate system," Nature, vol. 419, no. 6903, pp. 215-223, 2002.

[2] C. E. Adler and G. Hirsch Hadorn, "The IPCC and treatment of uncertainties: topics and sources of dissensus," Wiley Interdisciplinary Reviews: Climate Change, vol. 5, no. 5, pp. 663-676, 2014.

[3] M. O. Andreae, C. D. Jones, and P. M. Cox, "Strong present-day aerosol cooling implies a hot future," Nature, vol. 435, no. 7046, pp. 1187-1190, 2005.

[4] H. Yu, Y. J. Kaufman, M. Chin et al., "A review of measurementbased assessments of the aerosol direct radiative effect and forcing," Atmospheric Chemistry and Physics, vol. 6, no. 3, pp. 613-666, 2006.

[5] O. Torres, P. K. Bhartia, J. R. Herman, Z. Ahmad, and J. Gleason, "Derivation of aerosol properties from satellite measurements of backscattered ultraviolet radiation: theoretical basis," Journal of Geophysical Research D, vol. 103, no. 14, pp. 17099-17110, 1998.

[6] J. Hansen, M. Sato, and R. Ruedy, "Radiative forcing and climate response," Journal of Geophysical Research D: Atmospheres, vol. 102, no. 6, pp. 6831-6864, 1997.

[7] Y. J. Kaufman, D. Tanré, O. Dubovik, A. Karnieli, and L. A. Remer, "Absorption of sunlight by dust as inferred from satellite and ground-based remote sensing," Geophysical Research Letters, vol. 28, no. 8, pp. 1479-1482, 2001.

[8] M.-K. Kim, W. K. M. Lau, K.-M. Kim, and W.-S. Lee, "A GCM study of effects of radiative forcing of sulfate aerosol on large scale circulation and rainfall in East Asia during boreal spring," Geophysical Research Letters, vol. 34, no. 24, Article ID L24701, 2007.

[9] A. Pozzer, A. De Meij, J. Yoon, H. Tost, A. K. Georgoulias, and M. Astitha, "AOD trends during 2001-2010 from observations and model simulations," Atmospheric Chemistry and Physics, vol. 15, no. 10, pp. 5521-5535, 2015.

[10] T. F. Eck, B. N. Holben, J. S. Reid et al., "Wavelength dependence of the optical depth of biomass burning, urban, and desert dust aerosols," Journal of Geophysical Research, vol. 104, no. 24, pp. 31333-31349, 1999.

[11] O. Dubovik, B. Holben, T. F. Eck et al., "Variability of absorption and optical properties of key aerosol types observed in worldwide locations," Journal of the Atmospheric Sciences, vol. 59, no. 3, pp. 590-608, 2002.

[12] M. Balarabe, K. Abdullah, and M. Nawawi, "Seasonal Variations of Aerosol Optical Properties and Identification of Different Aerosol Types Based on AERONET Data over Sub-Sahara West-Africa," Atmospheric and Climate Sciences, vol. 06, no. 01, pp. 13-28, 2016.

[13] J. Lee, J. Kim, C. H. Song et al., "Characteristics of aerosol types from AERONET sunphotometer measurements," Atmospheric Environment, vol. 44, no. 26, pp. 3110-3117, 2010.

[14] A. H. Omar, J. Won, D. M. Winker, S. Yoon, O. Dubovik, and M. P. McCormick, "Development of global aerosol models using cluster analysis of Aerosol Robotic Network (AERONET) measurements," Journal of Geophysical Research, vol. 110, no. 10, pp. 1-14, 2005.

[15] R. C. Levy, L. A. Remer, and O. Dubovik, "Global aerosol optical properties and application to Moderate Resolution Imaging Spectroradiometer aerosol retrieval over land," Journal of Geophysical Research Atmospheres, vol. 112, no. 13, Article ID D13210, 2007.

[16] Y. Qin and R. M. Mitchell, "Characterisation of episodic aerosol types over the Australian continent," Atmospheric Chemistry and Physics, vol. 9, no. 6, pp. 1943-1956, 2009.

[17] K. H. Lee and Y. J. Kim, "Satellite remote sensing of Asian aerosols: a case study of clean, polluted, and Asian dust storm days," Atmospheric Measurement Techniques, vol. 3, no. 6, pp. 1771-1784, 2010.

[18] P. J. Sheridan, D. J. Delene, and J. A. Ogren, "Four years of continuous surface aerosol measurements from the Department of Energy's Atmospheric Radiation Measurement Program Southern Great Plains Cloud and Radiation Testbed site," Journal of Geophysical Research Atmospheres, vol. 106, no. 18, Article ID 2001JD000785, pp. 20735-20747, 2001.

[19] W. Zhang, X. Gu, H. Xu, T. Yu, and F. Zheng, "Assessment of OMI near-UV aerosol optical depth over Central and East Asia," Journal of Geophysical Research: Atmospheres, vol. 121, no. 1, pp. 382-398, 2016.

[20] L. Wu and Q.-C. Zeng, "Classifying Asian dust aerosols and their columnar optical properties using fuzzy clustering," Journal of Geophysical Research Atmospheres, vol. 119, no. 5, pp. 2529-2542, 2014.

[21] S. D. Xie, Z. Liu, T. Chen, and L. Hua, "Spatiotemporal variations of ambient PM10 source contributions in Beijing in 2004 using positive matrix factorization," Atmospheric Chemistry and Physics, vol. 8, no. 10, pp. 2701-2716, 2008.

[22] X. Zhao, X. Zhang, W. Pu, W. Meng, and X. Xu, "Scattering properties of the atmospheric aerosol in Beijing, China," Atmospheric Research, vol. 101, no. 3, pp. 799-808, 2011.

[23] X. Zheng, X. Liu, F. Zhao, F. Duan, T. Yu, and H. Cachier, "Seasonal characteristics of biomass burning contribution to Beijing aerosol," Science in China, Series B: Chemistry, vol. 48, no. 5, pp. 481-488, 2005.

[24] B. Guinot, H. Cachier, J. Sciare, Y. Tong, W. Xin, and Y. Jianhua, "Beijing aerosol: atmospheric interactions and new trends," 
Journal of Geophysical Research: Atmospheres, vol. 112, no. 14, Article ID D14314, 2007.

[25] X. He, C. C. Li, A. K. Lau et al., "An intensive study of aerosol optical properties in Beijing urban area," Atmospheric Chemistry and Physics, vol. 9, no. 22, pp. 8903-8915, 2009.

[26] P. Liu, C. Zhao, Q. Zhang et al., "Aircraft study of aerosol vertical distributions over Beijing and their optical properties," Tellus $B$, vol. 61, no. 5, 2009.

[27] X. Yu, B. Zhu, Y. Yin, J. Yang, Y. Li, and X. Bu, "A comparative analysis of aerosol properties in dust and haze-fog days in a Chinese urban region," Atmospheric Research, vol. 99, no. 2, pp. 241-247, 2011.

[28] X. Yu, C. Shi, J. Ma et al., "Aerosol optical properties during firework, biomass burning and dust episodes in Beijing," Atmospheric Environment, vol. 81, pp. 475-484, 2013.

[29] H. Che, X. Xia, J. Zhu et al., "Aerosol optical properties under the condition of heavy haze over an urban site of Beijing, China," Environmental science and pollution research international, vol. 22, no. 2, pp. 1043-1053, 2015.

[30] J. C. Bezdek, Pattern Recognition with Fuzzy Objective Function Algorithms, Plenum Press, New York, NY, USA, 1981.

[31] B. N. Holben, T. F. Eck, I. Slutsker et al., "AERONET-a federated instrument network and data archive for aerosol characterization," Remote Sensing of Environment, vol. 66, no. 1, pp. 1-16, 1998.

[32] O. Dubovik, A. Smirnov, B. N. Holben et al., "Accuracy assessments of aerosol optical properties retrieved from Aerosol Robotic Network (AERONET) Sun and sky radiance measurements," Journal of Geophysical Research D: Atmospheres, vol. 105, no. 8, pp. 9791-9806, 2000.

[33] G. S. Brown, "The validity of shadowing corrections in rough surface scattering," Radio Science, vol. 19, no. 6, pp. 1461-1468, 1984.

[34] C. F. Bohren and D. R. Huffman, Absorption and Scattering of Light by Small Particles, Wiley-VCH, Weinheim, Germany, 1998.

[35] K. Okada, J. Heintzenberg, K. Kai, and Y. Qin, "Shape of atmospheric mineral particles collected in three Chinese aridregions," Geophysical Research Letters, vol. 28, no. 16, pp. 31233126, 2001. 

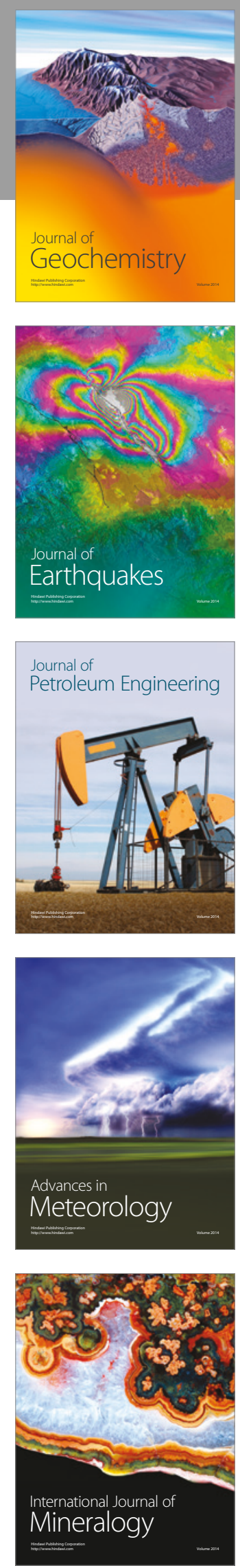
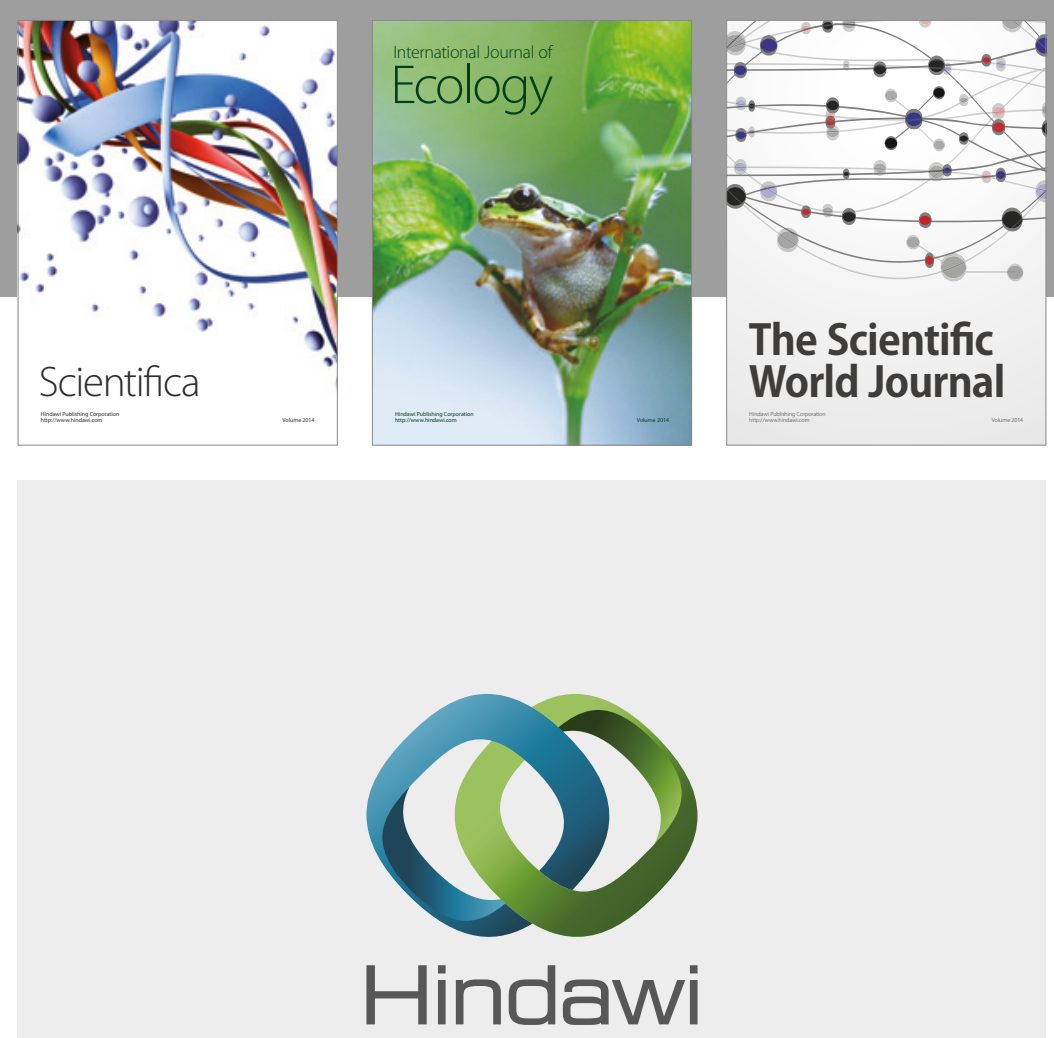

Submit your manuscripts at

https://www.hindawi.com
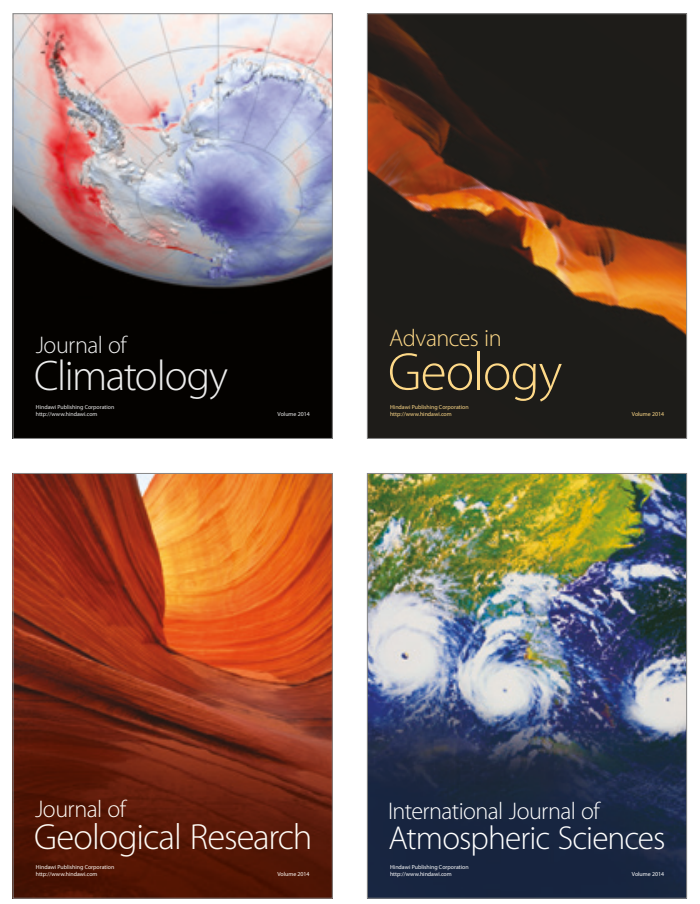

The Scientific

World Journal
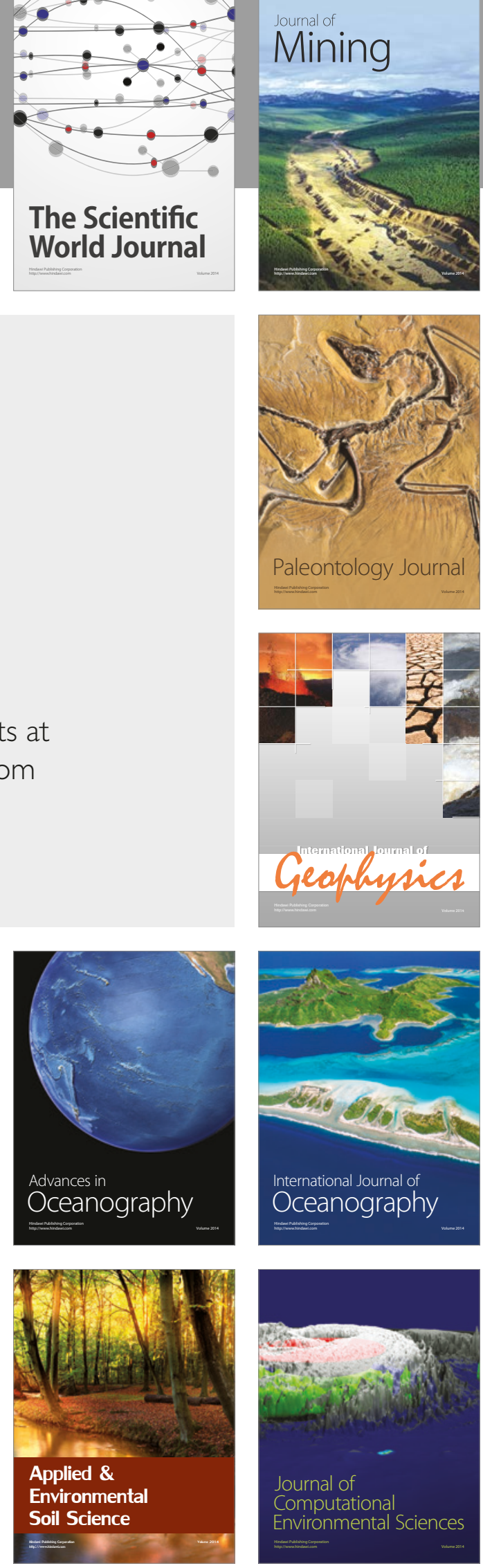